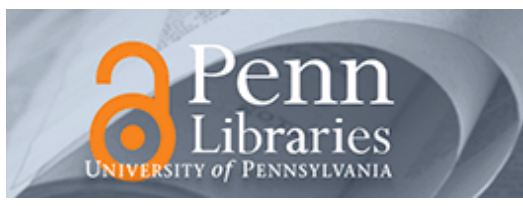

University of Pennsylvania ScholarlyCommons

Wharton Pension Research Council Working

Papers

Wharton Pension Research Council

9-1-2008

\title{
Reforming Social Security with Progressive Personal Accounts
}

John Geanakoplos

Yale University, john.geanakoplos@yale.edu

Stephen P.Zeldes

Columbia University, stephen.zeldes@columbia.edu

Follow this and additional works at: https://repository.upenn.edu/prc_papers

Part of the Economics Commons

Geanakoplos, John and Zeldes, Stephen P., "Reforming Social Security with Progressive Personal Accounts" (2008). Wharton Pension Research Council Working Papers. 239.

https://repository.upenn.edu/prc_papers/239

This paper is posted at ScholarlyCommons. https://repository.upenn.edu/prc_papers/239

For more information, please contact repository@pobox.upenn.edu. 


\title{
Reforming Social Security with Progressive Personal Accounts
}

\begin{abstract}
The heated debate about how to reform Social Security has come to a standstill because the view of most Democrats (that Social Security must be a defined benefits plan similar in spirit to the current system) seems irreconcilable with the proposals supported by many Republicans (to create a defined contribution system of personal accounts holding marketed assets). We describe a system of "progressive personal accounts" that preserves the core goals of both parties, and that is self-balancing on an ongoing basis. Progressive personal accounts have two critical features: (1) accruals into the personal accounts would be exclusively in a new kind of derivative security (which we call a PAAW for Personal Annuitized Average Wage security) that pays its owner one inflation-corrected dollar during every year of life after his statutory retirement date, multiplied by the economy wide average wage at the retirement date and (2) households would buy their new PAAWs each year with their social security contributions, augmented or reduced by a government match that would add to contributions from households with low lifetime incomes by taking from households with high lifetime incomes. PAAWS define benefits and achieve risk sharing across generations, as Democrats would like, yet can be held in personal accounts with market valuations, as Republicans propose.
\end{abstract}

\section{Keywords}

Social Security, personal accounts, risk-sharing

\section{Disciplines}

Economics 


\title{
Reforming Social Security with Progressive Personal Accounts
}

\author{
John Geanakoplos and Stephen P. Zeldes
}

September 2008

\section{PRC WP2008-11 \\ Pension Research Council Working Paper Pension Research Council \\ The Wharton School, University of Pennsylvania \\ 3620 Locust Walk, 3000 SH-DH \\ Philadelphia, PA 19104-6302}

Tel: 215.898.7620 Fax: 215.573.3418

Email: prc@wharton.upenn.edu

http://www.pensionresearchcouncil.org

\begin{abstract}
We thank Ryan Chahrour, Theodore Papageorgiou, and Allison Schrager for research assistance, and Andrew Biggs, Jeffrey Brown, Jason Furman, Jeffrey Liebman, Deborah Lucas, Kent Smetters, and Salvador Valdes-Prieto for helpful comments and suggestions. This research was supported by the U.S. Social Security Administration through grant \#10-P-98363-1 to the National Bureau of Economic Research as part of the SSA Retirement Research Consortium. Opinions and errors are solely those of the authors and not of the institutions with whom the authors are affiliated. (C) 2008 Pension Research Council of the Wharton School of the University of Pennsylvania. All rights reserved.
\end{abstract}




\title{
Reforming Social Security with Progressive Personal Accounts
}

\author{
John Geanakoplos and Stephen P. Zeldes
}

\begin{abstract}
$\underline{\text { Abstract }}$
The heated debate about how to reform Social Security has come to a standstill because the view of most Democrats (that Social Security must be a defined benefits plan similar in spirit to the current system) seems irreconcilable with the proposals supported by many Republicans (to create a defined contribution system of personal accounts holding marketed assets). We describe a system of "progressive personal accounts" that preserves the core goals of both parties, and that is self-balancing on an ongoing basis. Progressive personal accounts have two critical features: (1) accruals into the personal accounts would be exclusively in a new kind of derivative security (which we call a PAAW for Personal Annuitized Average Wage security) that pays its owner one inflation-corrected dollar during every year of life after his statutory retirement date, multiplied by the economy wide average wage at the retirement date and (2) households would buy their new PAAWs each year with their social security contributions, augmented or reduced by a government match that would add to contributions from households with low lifetime incomes by taking from households with high lifetime incomes. PAAWS define benefits and achieve risk sharing across generations, as Democrats would like, yet can be held in personal accounts with market valuations, as Republicans propose.
\end{abstract}

Keywords: Social Security, personal accounts, risk-sharing

JEL classification numbers: E6, H55, D91

\section{John Geanakoplos}

Cowles Foundation

Economics Department

Yale University

New Haven, CT

203-432-3397

Santa Fe Institute, Santa Fe New Mexico

john.geanakoplos@yale.edu

\section{Stephen P. Zeldes}

Graduate School of Business

Columbia University

3022 Broadway

New York, NY 10027-6902

212-854-2492

stephen.zeldes@columbia.edu 


\section{Introduction and related literature}

In recent years, the United States has been engaged in a heated debate about whether to replace part of the current, defined benefit (DB) Social Security system with a system of defined contribution (DC) personal accounts. In 2005, President Bush gave speeches in numerous cities and towns advocating a reform that included these individual accounts. Both proponents and opponents of individual accounts have emphasized the stark differences between the current defined benefit system and a system with individual accounts. The mechanics and outcomes of the two systems seem to be quite different, and their goals are usually presented as diametrically opposed.

Advocates of preserving the current system (predominantly Democrats) are committed to four core goals that stem from regarding Social Security as social insurance: (1) social security should redistribute wealth from those who have earned more over their whole working lives to those who have earned less, (2) different generations should share the risks of aggregate shocks, (3) workers should be insured against inflation and long life with indexed life annuities, and (9) there should be limited opportunity for individuals to make mistakes that would lower their standard of living during retirement.

Advocates of shifting to a personal account system for Social Security (predominantly Republicans) base their support on a commitment to a set of core goals that stem from a desire for real social security, specifically (4) ownership by individuals of tangible assets that cannot be revoked by a future government, (5) transparency regarding accrual of those assets, so that workers know what they own, (6) market valuations of assets as they are accrued so that rational planning for retirement can take place outside of social security and so that (7) workers know how much their wages are being taxed or subsidized by the social security system, (8) equity-like returns on at least some of those assets, and (10) the opportunity for individuals to make choices about the allocation of assets in their portfolio.

Our purpose is to find common ground between these two approaches that preserves the core goals (1)-(8) of each, while compromising on portfolio choice (9) 
versus (10). We show that it is perfectly possible to convert social security into a system of personal accounts, with irrevocable ownership of market priced assets, while at the same time redistributing benefits based on lifetime income and sharing risks across generations. We call this system progressive personal accounts. Moreover, we envisage this system of progressive personal accounts automatically balancing the social security budget.

There are two crucial ingredients in progressive personal accounts. First, benefits would be awarded in the form of a new kind of derivative security that pays a worker a life annuity that is proportional to the economy-wide average labor earnings in his (statutory) retirement year. We call this security a Personal Annuitized Average Wage security, or PAAW. This security explicitly delivers payouts that achieve risk sharing across generations, since retiree benefits move in lock step with worker wages. Second, PAAWs would be awarded based on worker contributions plus a government match that is more favorable for workers with low lifetime earnings. This variable match redistributes wealth, transferring benefits from those households with high realized lifetime earnings to households in the same generation which have low lifetime earnings. ${ }^{1}$

Opposition to personal accounts has arisen in part from the belief that personal accounts would necessarily violate desiderata (1)-(3). We show that on the contrary, progressive personal accounts are consistent with (1)-(3). Furthermore, we envisage active market trading in PAAWs, and thus a continuously evolving market price for PAAWs, giving PAAW owners a market rate of return. We shall argue that progressive personal accounts also satisfy Republican goals (4)-(8). Thus they provide a clear starting point for a bipartisan effort to reform and improve the current Social Security system. $^{2}$

A growing number of countries have moved away from the pay-as-you-go type social security system still used in the United States. Some countries (e.g. Chile) have

\footnotetext{
${ }^{1}$ Wealth redistribution from high lifetime earners to low lifetime earners can also be regarded as intragenerational risk sharing.

${ }^{2}$ Of course, care must be exercised in the implementation, as there is a danger that support for progressive personal accounts might get transmuted during the political process into support for traditional personal accounts that hold only stocks and bonds and have no government match.
} 
moved toward traditional individual account systems. Others (Sweden, Italy, and a number of other European countries) have adopted notional defined contribution accounts in which participants have "notional" account balances that earn a "notional" rate of return, typically tied to the growth rate of wages. While progressive personal accounts bear some relation to each of these, we argue that progressive personal accounts are distinctly superior. First, they retain the intra-generational redistribution / risk-sharing missing from both traditional personal accounts and notional accounts. Second, they retain inter-generational risk-sharing, which traditional personal accounts do not. Third, they provide account balances that correspond to market value, and returns that are market rates of return, whereas notional accounts do not. For these reasons, progressive personal accounts would put the United States system back in the vanguard of managing lifetime financial security.

Our paper proceeds as follows. We begin with a brief overview of the tax and benefit rules of the current system. Next, we define a PAAW as a security that pays its designee one inflation-corrected dollar for every year of his life after a fixed date $t_{R}$ (the year he hits the statutory retirement age), multiplied by the economy-wide average wage at $t_{R}$. PAAWs are of course new and unfamiliar securities, but they are not fundamentally different from a host of other derivative securities introduced by Wall Street in recent years. A household holding PAAWs is sharing risk with the next generation, since higher wages for young workers in the future would imply larger PAAW dividends. The PAAWs also protect against long life and inflation, since at retirement they turn into indexed annuities.

Having defined a PAAW, we next show that the social security benefits promised under the current system can be neatly summarized by the number of PAAWs a household is entitled to. The current system is akin to a system of personal accounts in which households accrue nothing until retirement, and then (based on their lifetime earnings) suddenly accrue a large number of PAAWs that they can never sell. By specifying an accrual rule that enables households to accumulate PAAWs as they work, we show that it is possible to create a system of progressive personal accounts that gives retired workers the same benefits as the current system, and also gives them property rights over their PAAWs before retirement. At the very least, this demonstrates 
that there is no inherent contradiction between the current defined benefits system and an appropriately structured personal account system.

We explicitly describe two accrual rules specifying how workers might acquire ownership of PAAWs over their working lives. Both lead to ownership of the same number of PAAWs at retirement as is promised by the current social security benefit formula. The "fastest" accrual rule allocates property rights over PAAWs at the fastest rate consistent with never having to take back a PAAW and reaching the current benefit formula at retirement no matter what earnings history materializes. Though the "fastest" accrual rule is the simplest, we recommend instead an alternative called the "straight line" accrual rule because it makes the real tax or subsidy social security imposes on worker wages more transparent.

Next we describe how a market in PAAWs could be developed. We argue that PAAWs should be pooled, similar to the way individual mortgages are pooled by the government agencies Fannie Mae and Freddie Mac, and then traded. ${ }^{3}$ Investors would not buy individual PAAWs, but instead a pro rata share of a large pool of them. To eliminate adverse selection, and to guarantee a large, liquidly traded market, we would oblige all households to sell a small fixed percentage (e.g. 10\%) of their newly acquired PAAWs into the pools. A liquid PAAWs market would establish a market price for PAAWs, bringing the added transparency that comes with reliable valuations of assets.

PAAWs are tangible assets and thus, once accrued, difficult to revoke (4). Their accumulation in personal accounts would make benefits already accrued completely transparent (5). Once PAAWs became reliably priced by the market, the government could even less easily expropriate the PAAWs held in personal accounts because households would know exactly how much money they were losing (4). PAAW prices would enable individuals to compute a market value balance sheet to facilitate their financial planning (6). If the allocation of PAAWs per dollar of tax contributions followed the straight-line rule we describe later, then workers would quickly and easily see the true average match rate they faced (the percentage difference between the value of the additional PAAWs added to their social security accounts and the social security taxes

\footnotetext{
${ }^{3}$ Agency mortgage pools (in contrast to subprime mortgages) have been one of the most successful innovations in U.S. financial history.
} 
they paid), and statements could provide information on the marginal match rate as well, giving the system much more transparency than it has now (7). And over long time periods (e.g. 30 years), the increase in wages and the stock market are highly correlated. Thus over long horizons PAAWs would earn equity-like returns (8), while in the short run being far less volatile than equities as the worker approaches retirement. ${ }^{4}$

We also point out some additional benefits of a market for PAAWs. A liquid PAAWs market would enable the government to observe the market value of its new promises and its accrued social security liabilities. We argue that market value is a better and less arbitrary measure of liabilities than actuarial value. Moreover, a market for PAAWs would likely lead to a watershed in advancing annuities markets and other retirement markets.

At the same time, by forcing personal accounts to retain $90 \%$ of their PAAWs, including those awarded by the government match, we ensure that benefits are very similar to those of the current system and that households with smaller lifetime earnings get proportionately higher benefits (1). The holding of PAAWs also embodies the Democrats' desire for inter-generational risk-sharing (2) and inflation-hedged life annuities (3). Of course $90 \%$ is an arbitrary figure that could be negotiated. Republicans would tend to prefer more choice, and thus a lower number, and Democrats might prefer an even higher number. ${ }^{5}$

The last part of our paper takes up the question of budget balance, at the household level and for the system as a whole. Since the current Social Security system contains no budget balance mechanism at either level, a progressive personal accounts system that mimics the contributions and payouts of the current system would not either. We argue that social security should be made self-balancing at the aggregate level. This is especially important for plans such as this one that lock in

\footnotetext{
${ }^{4}$ The fact that PAAWs earn equity-like returns does not imply that shifting to personal accounts (these or traditional ones) would raise overall rates of return on Social Security contributions. See Geanakoplos, Mitchell, and Zeldes (1998) and the discussion in Section IV below.

${ }^{5}$ If the only source of market-traded PAAWs were sales from personal accounts, then the percent of PAAWs retained in accounts should be set low enough to lead to a liquid market in PAAWs. However, as we describe later, the government could instead issue extra individual PAAWs and sell them directly to pools in financial markets, leaving open the possibility that a liquid PAAW market could be created even with workers retaining $100 \%$ of their PAAWs.
} 
benefits by enhancing property rights on accrued benefits. We describe a system such that workers pay for their PAAWs with their social security taxes, augmented or reduced by a government match similar in spirit to that arising from the straight line accrual rule under the current benefit rules. But we impose the constraint that the total value of social security taxes should be equal to the total value of PAAWs awarded.

To make the discussion concrete, and since PAAWs are not currently marketed, we undertake a back-of-the-envelope calculation of their value. We simplify the calculation considerably by assuming risk-neutrality and computing expected values of payouts, but in related work (Geanakoplos and Zeldes, 2008) we treat valuation more thoroughly and specifically incorporate the effects of systematic market risk.

Once we obtain estimated market prices for pooled PAAWs of every vintage, we can value accrued PAAWs, and compare these numbers to the dollar contributions that generate the accruals. We define the government match for a household as the difference between the dollar value of extra PAAW accruals and the dollar value of the extra contributions generating those accruals, and the match rate as the match divided by the contributions. Depending on the accrual rule, this match rate may vary from year to year for the same household.

The match rates for any accrual rule that mimics the current system are non-zero for five reasons: a) the current system is not self-balancing, i.e. there is a disconnect between contributions and benefit rules, which Congressional interventions have often worsened, b) the current pay-as-you-go system uses part of current contributions to pay off the legacy debt incurred by the early generations who received benefits far in excess of their contributions, $c$ ) in the current system, the aggregate number of PAAWs accrued in any given year does not depend on the aggregate level of current social security contributions or on future wages, hence to the extent that current contributions are unusually low (high) and to the extent it can be foreseen that future wages will be much higher (or lower), accrued PAAWs will likely be worth more (or less) than contributions, d) depending on the speed of accrual, households might get better or worse annual deals when they are young or old, e) in the current system, households with low lifetime earnings receive more PAAWs per dollar of contributions. 
There are a number of ways to make the system self-balancing, each of which will by necessity alter the risk-sharing (and match rates) built into the current system. We propose a mechanism that ensures aggregate fiscal balance "on the way in", i.e. that sets the market value of annual aggregate accrued PAAWs equal to annual contributions, but that retains all the desiderata (1)-(8). This mechanism would eliminate reasons a), b) and c) for non-zero household match rates, but retain reason e), and possibly reason d) as well. This is consistent with the principle that households making low lifetime contributions (because of low lifetime incomes) should get a positive government match, and households with high contributions should get a negative government match. Fiscal balance "on the way out" could be ensured by requiring the government, or the private sector, to use the social security trust fund to hedge social security liabilities.

As part of ensuring fiscal balance on the way in, we would first recognize the legacy debt of the current system by giving PAAWs to all workers and retirees according to what they have already accrued under the old rules. (Naturally what this amounts to requires explanation.) This would represent new explicit debt to the government. The government could finance future interest and principal payments both by issuing new Treasury debt (i.e. rolling over the debt) and by raising general taxes. In this way the legacy debt would be removed from the social security system and be paid by all (current and future) entities subject to general taxes, like corporations and investors earning dividend income, and not just by workers. We calculate that this tax would amount to about $1 \%$ on all income. Then, every year from now on, households would have to pay for their own PAAWs with their social security contributions, except that the government match would redistribute contributions from workers with high lifetime earnings to those with low lifetime earnings. In the aggregate, the social security system would then be fully funded and automatically balanced "on the way in". We estimate that at the current time, workers would be able to afford to buy just about the same benefits that they are implicitly accruing in the current social security system. The $1 \%$ general tax would thus enable a social security system that was in balance now and that would automatically stay in balance "on the way in" in the future. Over time, of course, the market value of the outstanding PAAWs would diverge from their original 
price. The government would have to hedge this risk, or as we explain below, engage the private sector in doing so.

\section{Related Literature}

Our work is related to and builds on a number of other papers in the literature. Feldstein and Samwick (1992) and Cushing (2005) compute the implicit marginal tax rate of the current U.S. Social Security system. Below, we show the relationship between their calculations of marginal tax rates and our calculations of marginal match rates. Geanakoplos, Mitchell, and Zeldes (1999) discuss alternative ways to compute accrued social security benefits, and Jackson (2004) describes a system of accrual accounting that he argues would more clearly describe social security's financial situation. Feldstein and Liebman (2002) analyze the redistributive features of an individual account plan with a two-tier contribution structure in which part of the inflows are proportional to earnings and part are lump-sum contributions. Vickrey (1947) and Liebman (2003) discuss the advantages of basing taxation on lifetime rather than annual income. Valdes-Prieto (2000), Borsch-Supan (2005), and Auerbach and Lee (2006) analyze notional DC systems, such as those adopted in Sweden and Germany, and the self-adjustment mechanisms built into them.

A number of papers have proposed the creation of related new financial securities. For example, Shiller (1993) proposes GDP-linked securities, Blake and Burrows (2001) proposes longevity or survivor bonds, and Bohn (2002) and Goetzmann (2005) propose aggregate wage-related securities. Valdes-Prieto (2005) advocates creating "pay-as-you-go securities" (which would securitize the part of future social security contributions that represents a net tax), and using them as a basis for social security reform.

\section{The mechanics of progressive personal accounts}

In this section, we first briefly describe how the current U.S. Social Security system works, i.e. the tax and benefit rules. We then show that it is possible to create a system of individual accounts that exactly replicates the current system. This means 
that personal accounts can be compatible with progressivity and intergenerational risk sharing.

In the current system the benefits received by social security contributors are based on a concave function of lifetime earnings, providing smaller increments in benefits with each additional dollar of lifetime earnings. While personal accounts as typically implemented eliminate this progressivity, we show that this need not be the case. Personal accounts can be made progressive simply by making annual PAAW accruals depend on the size of accumulated past accruals. Later in the paper, we show that this is equivalent to providing a variable government match (positive or negative) where the size of the match depends on accumulated accruals to date.

Personal accounts, by virtue of being personal, would also seem to eliminate the intergenerational risk sharing that is built into the current system. In the current system, retiree benefits depend on the wages of the next generations of workers. As the young do better, so will the old, and vice versa. If the personal accounts hold stocks and bonds it is quite possible that retiree benefits will move in the opposite direction from wages, at least for some cohorts. But there is no reason the personal accounts should be confined to traditional investment securities. We explain that by holding PAAWs, retirees will receive payouts that move in the same direction as the wages of the next generation of workers.

\section{A. The current system}

We start by describing the current contribution and benefit rules for the U.S. Social Security system; we ignore adjustments that would have to occur in the event that the system is unable to meet its obligations. For simplicity, we focus on an individual who will be single and childless throughout life, who will not become disabled, and who will retire at the "normal retirement age" specified by Social Security. ${ }^{6}$

Program rules mandate that individuals and their employers together contribute 12.4 percent of all "covered" earnings, defined as earnings below the social security earnings cap (the annual earnings cap equaled $\$ 102,000$ in 2008). No contributions are

\footnotetext{
${ }^{6}$ See Section C2 below for a sketch of how the analysis could be extended to include spouses and children (and their associated program benefits), as well as early or delayed retirement.
} 
collected on earnings above the cap. Of the 12.4 percent, 1.8 percentage points are earmarked for disability coverage. In the analysis that follows, we ignore DI coverage, and therefore use a social security contribution rate of 10.6 percent.

The benefits under the current system are a function of the worker's lifetime "covered" earnings history. An important feature of the system is that it is "wageindexed": (1) the earnings that enter the benefit function are individual earnings in any year divided by average economy-wide earnings in that year, (2) initial benefits upon retirement are scaled by average economy-wide earnings in the statutory retirement year, and (3) the earnings cap and the "bend points" defined below are adjusted so that their ratios to the average economy-wide earnings remain constant over time. ${ }^{7}$ As a result, the system can be described more easily and clearly by defining a set of "relative" variables that are equal to the dollar amounts divided by average economywide earnings for the year. We define relative earnings for a worker in any year $t$ as his current covered earnings for that year divided by average economy-wide earnings, and average relative earnings as the average of his highest 35 values of relative earnings. ${ }^{8}$

We can use these variables to describe the promised benefit structure of the current U.S. Social Security system. Initial relative benefits are defined by the concave function of average relative earnings given in figure 1a. Initial relative benefits are equal to $90 \%$ of average relative earnings that are less than .24, plus $32 \%$ of average relative

\footnotetext{
${ }^{7}$ Average economy-wide earnings for a given year is the average across workers of annual labor earnings in that year. (We use the terms "labor income", "wage income", "labor earnings", "earnings", and "wages" interchangeably in this paper). SSA's measure of average economy-wide earnings is the Average Wage Index (AWI). They compute the AWI sequentially, by first constructing a "raw earnings growth rate" $g(t)$, and using this to construct the next $A W I$ level, i.e. $A W I(t)=(1+g(t)){ }^{*} A W I(t-1)$. Various techniques have been used over time to construct the raw earnings growth rate. Since 1991, the Social Security Administration has calculated the "raw" growth based on employer-reported W-2 forms, summing all earnings (including amounts above the Social Security earnings cap), including deferred compensation, less distributions, and dividing by the total number of earners. From 1985 to 1990, the measure excluded deferred compensation and distributions. Prior to 1985, growth was calculated using earnings measurements provided by the Internal Revenue Service. Because the SSA has used varied methods to compute earnings growth, the current level of the AWI series does not equal the level of "raw" average earnings computed by the SSA. Under the current computation method, the AWI is about 4\% larger than the "raw" series. See Clingman and Kunkel (1992), Donkar (1981), and SSA (2006). Benefits after retirement are indexed to the Consumer Price Index.

${ }^{8}$ We ignore for simplicity the program rule that, in calculating average earnings over a career, earnings prior to age 60 are indexed forward to age 60 wage levels using Social Security's Average Wage Index, while earnings from age 60 and after are included at their nominal levels. Our definition assumes all earnings are indexed.
} 
earnings between .24 and 1.35 , plus $15 \%$ of average relative earnings between 1.35 and $1.99 .^{9}$

A worker's initial dollar benefits (also referred to as the Primary Insurance Amount or PIA) are paid at his statutory "normal retirement age" (NRA). They are equal to initial relative benefits multiplied by average economy-wide earnings in that year. Benefits in subsequent years are indexed to the CPI, so that individuals receive a constant stream of real benefits for as long as they live.

Another way of describing the initial relative benefit function is to say that by the end of their working lives, workers will fall into one of three lifetime earnings categories, and that the marginal benefit a worker receives per dollar contributed in taxes depends on his category. If a worker about to retire had increased his relative earnings in any one previous year by $\Delta$, he would have made extra tax contributions of $\Delta \times 10.6 \%$ (assuming a social security tax of $10.6 \%$ ) measured in average wage units. (His dollar contribution would be that number multiplied by the economy-wide average wage for the year). According to the formula just described above, the worker thereby would have increased his lifetime average relative earnings by $\Delta / 35$. For a worker with very low lifetime earnings, this would have increased his initial relative benefits by $.9 \times \Delta / 35$, as in figure $1 \mathrm{~A}$. For this worker, the extra initial benefit per additional contribution (measured in relative wage units is) $(.9 \times \Delta / 35) /(\Delta \times 10.6 \%) \approx .24$. For a worker with somewhat higher lifetime earnings, the corresponding number is $(.32 \times \Delta / 35) /(\Delta \times 10.6 \%) \approx .09$. For a higher earnings worker, the number is $(.15 \times \Delta / 35) /(\Delta \times 10.6 \%) \approx .04 .^{10} \mathrm{We}$ present these marginal benefit brackets in figure $2 a$.

Note that since benefits are determined by relative earnings, a temporary and proportional increase in the earnings of all workers in any year $t$ will leave unchanged the benefits that those workers receive when they retire in year $t_{R}>t$. The benefits of individuals reaching the statutory retirement age in year $t$ would be proportionately higher in year $t$ and each year they live thereafter.

\footnotetext{
${ }^{9}$ The points at which the slope of the line change are referred to as "bend points". We ignore here the rule that individuals must earn income in a minimum of 40 quarters in order to receive benefits.

${ }^{10}$ This exercise assumes that the increase $\Delta$ in relative earnings occurred in one of the 35 highest
} 


\section{B. Defining new securities -- PAAWs}

We define a Personal Annuitized Average Wage security or PAAW as a security that pays its owner one inflation-corrected dollar for every year of his life after a fixed date $t_{R}$ (the year he hits the statutory retirement age $R$ ), multiplied by the economy-wide average wage at $t_{R}$. PAAWs are tied to specific individuals (i) and to the year of the first payout on the security $\left(t_{R}\right)$, and we use the notation $\operatorname{PAAW}\left(i, t_{R}\right)$ to capture this.

We also define two other securities that could help in the construction and pricing of PAAWs. First, we define a PANT( $\left.i, t_{R}\right)$ (personal annuity unit) as a person-i-specific "year $t_{R}$ annuity unit" as a security that pays one dollar in year $t_{R}$ and one inflationadjusted dollar in every subsequent year that the individual $i$ is alive. Second, we define an Average Wage(t) Security as a security with a single payout in year t equal to the average economy-wide earnings in that year. An alternative way of describing a PAAW is that it is a composite security that pays off one PANT $\left(i, t_{R}\right)$ for every dollar paid in year $t_{R}$ by the Average Wage $\left(t_{R}\right)$ Security.

A PAAW (as well as a PANT or an Average Wage Security) is a derivative security, similar to countless others that have been created in recent years by Wall Street. Because the security is partly an annuity, it provides insurance for long life, paying every year until death. Furthermore, because the payment depends on the average wage at retirement, it creates risk sharing across generations. If young workers are doing well and receiving high wages, the old will get higher payoffs from their PAAWs, and conversely.

\section{Translating the current system into an equivalent DC system}

We are now in a position to translate the current system into an equivalent defined contribution system, i.e. to show that by choosing a particular variable match, and restricting accounts to hold PAAWs, it is possible to create a system of progressive personal accounts that exactly mimics the promised taxes and payouts of the current system. Replicating the current system may not be the best way to implement individual accounts, but it serves as a starting point that allows one to compare and contrast the current system (translated into the language of DC) with the more standard

relative-earnings years (otherwise there would be no incremental benefit). 
DC systems typically proposed. We argue that this is an important step toward improving communication between the two sides of the current social security debate, potentially easing the political gridlock that has occurred in the U.S.

In order to replicate the current system, workers would receive PAAWs in exchange for their social security contributions, which they would hold in their personal accounts; workers would be prohibited from selling them. Later we consider both the advantages and disadvantages of allowing workers to sell some of their PAAWs in exchange for other financial securities, and also the advantages of observing a public market price for PAAWs.

To replicate the current system, workers and employers would (as in the current system) together contribute 10.6 percent of earnings up to the earnings cap. The government would credit each individual's account with a number of PAAWs; the exact number credited would depend (in a way to be specified) on current and past contributions. At the normal retirement age, each PAAW would pay off a dollar amount equal to the average wage in the economy in that year, and then in every subsequent year of life, the same inflation-indexed real payment. ${ }^{11}$

The current system redistributes from rich to poor on the basis of lifetime income, through the computation of benefits at the age of retirement. A natural question is whether we can replicate this redistribution in personal accounts, where the benefits are irrevocably owned by the account as they are earned, long before one's lifetime earnings can be measured. At first glance this seems impossible. But we show that by making new accruals depend on accumulated balances, as well as new contributions, we can indeed achieve the lifetime redistribution in the current system.

\section{Computing accrued balances (total and incremental)}

We define PBAL it to be the number of units of PAAWs $\left(i, t_{R}\right)$ accrued by worker $i$ as of year $t$. There are actually many rules for the accumulation of balances PBAL ${ }_{\text {it }}$ that can replicate the current system. The simplest is to define PBAL $L_{i t}$ as the benefits worker i would be entitled to under the current system given his earnings history up through year $t$, and assuming all his future earnings were zero. Clearly with such a

\footnotetext{
${ }^{11}$ Equivalently, at retirement each PAAW is transformed into a number of PANTs equal to the economywide average wage that year.
} 
definition $\mathrm{PBAL}_{\text {it }}$ can rise, but can never fall. There are other methods of accrual that also end with the same amount at retirement and never fall, but among them our definition accumulates balances most rapidly. We shall call it the fastest accrual rule. Later in this section, we examine a second accrual rule that we refer to as straight-line accrual.

Under the "fastest accrual rule" definition, progressive personal accounts can be described by simply changing the units on the axes in figures $1 \mathrm{a}$ and $2 \mathrm{a}$. These are presented in figures $1 \mathrm{~b}$ and $2 \mathrm{~b}$. For figure $1 \mathrm{~b}$, the $\mathrm{Y}$-axis is now relabeled as PBAL. For figure $2 \mathrm{~b}$, the $\mathrm{Y}$-axis is "additional PAAWs per additional contribution" and the $\mathrm{X}$ axis is PBAL. (Since the PBAL function defined in Figure $1 \mathrm{~b}$ is strictly monotone in average relative wage, we can replace each average relative wage on the $X$ axis of Figure $2 a$ with the corresponding PBAL, giving Figure $2 b$.) Figure $2 b$ shows the extra PAAWs divided by the extra contributions that together arise from working an additional hour (holding constant the number of years of work), as a function of how many PAAWs have already been accumulated. Additional PAAWs per additional contribution (measured in relative wages units) is a decreasing function of PBAL, falling from .24 to .09 to .04 as PBAL increases from less than .2 to more than $.54 .^{12}$

It might have seemed that our definition of PBAL ${ }_{\text {it }}$ would need to be a function of all of worker i's relative wages before year $t$. But Figure $2 b$ makes clear that $P B A L_{i t}$ can be rewritten as a function of just (PBAL $\mathrm{L}_{\mathrm{it}-1}$, Contribution(t)), provided that for a contribution coming after the first 35 years, only the excess of that contribution over the 35th highest relative contribution to date counts toward PAAW accrual.

PAAW accrual replicates the redistribution in the current system, and PAAW accrual is a function of 1) new contributions and 2) accumulated balances PBAL. This definition of PAAW accrual shows that we can award irrevocable benefits to young workers and yet still make total benefits accrued at retirement depend on lifetime earnings.

We illustrate how this accrual works in four examples, based on different assumed age - relative earnings profiles. For worker 1 (the "economy average" worker),

\footnotetext{
12 In the current system there is a 10 year vesting period, so we are referring here to workers in their $11^{\text {th }}$ year, or to workers in earlier years if we ignore the vesting requirement.
} 
we assume that earnings equal average economy-wide earnings in every year, i.e. that relative earnings equal 1. For worker 2, (the "average earner worker") we assume relative earnings at each age equal average relative earnings at the same age for the cohort of men born in $1937 .{ }^{13}$ For worker 3 (the "low earner" worker), we suppose that relative earnings equal one-half the relative earning of worker 2. For worker 4 (the "high earner" worker), we assume that relative earnings are 1.5 times the relative earnings of worker 2. Our results are shown in Figures 3-5. ${ }^{14}$

Figure 3 plots additional PAAWs per additional relative contribution against time, for each of the four workers. This can be interpreted as the extra PAAWs per unit of extra contribution that would accrue from working an extra hour (holding constant the number of years worked) now plotted against age. This graph shows how fast workers move along the schedule in Figure $2 \mathrm{~b}$. The average earner and the high earner both eventually move down to the .04 ratio, but the high earner worker gets there sooner. The economy average worker and the low earner worker never earn enough to move all the way to the .04 ratio. (The economy average worker starts at .24 ratio, and ends in the .09 ratio. The low earner worker does the same, but takes longer to get to the .09 ratio.) Notice that there is no drop after 35 years, because earnings late in life are always greater than or equal to the 35th highest. ${ }^{15}$ Hence, on the margin, an additional contribution would yield the full additional benefit.

Note that extra PAAWs are accrued due to increases in relative earnings (and contributions). If the earnings of all workers rise proportionately (due to either higher work hours or higher wages per hour), relative earnings remain unchanged and therefore workers will not accrue any additional PAAWs as a result of this change.

In Figure 4, we illustrate the annual change in PAAW balances at each age for the four workers. These graphs measure absolute increments over the year, rather

\footnotetext{
${ }^{13}$ We are grateful to Seung An from the Social Security Administration for providing us with the data on average cohort earnings. These men earned more than the economy wide average at every age over 28.

${ }^{14}$ Although we have not done so, our approach could easily be extended to examine realizations of a stochastic earnings process

${ }^{15}$ Note that it is purely by coincidence that worker 2 (cohort average) accumulates enough PAAWs to drop to the .04 ratio at exactly the same date that the worker has worked 35 years. Thus the drop after age 54 in figure 3 for worker 2 is unrelated to having worked 35 years at that point.
} 
than the increment per unit of contribution as in figure 3 . They therefore take into account the varying contributions due to the age profile of relative earnings. After year 35 , a large fraction of each contribution does not count toward accrual - all that counts toward accrual is the difference between relative earnings and the $35^{\text {th }}$ highest relative earnings.

Finally, in Figure 5, we look at the level of accrued PAAW balances (PBAL) versus age. The average worker (worker 1 ) accumulates enough securities to receive about 44 percent of the average wage in his first year of retirement. The cohort average worker (worker 2) accumulates enough securities to receive almost 60 percent of the average wage in his first year of retirement. The fact that this is less than twice the 36 percent accumulated by the low earner worker 3 (who earns half as much) illustrates again the redistribution in the system.

\section{Incorporating other social security benefits and features into}

\section{progressive personal accounts}

In the analysis above, we focused on single individuals with no children who retired at the normal retirement age with no chance of disability. We also ignored the requirement that only workers with 40 quarters of positive earnings are eligible to collect retirement benefits. We could extend our analysis to incorporate these minimum work requirements, as well as spousal benefits, survivor benefits, early or delayed retirement, and disability. For example, the accrual rules could be changed so that all PAAWs become vested only after 40 quarters of work. In addition, spousal benefits could be implemented through the creation of a separate spousal account. To replicate the current system, the accrual of PAAWs in this account would depend on the current contributions of both the individual and the spouse, as well as the accumulated balances of each individual. The accounts would become vested only after 10 years of marriage to match the requirement in the current system that divorced spouses must have been married for 10 years or more to receive spousal benefits. Finally, individuals wishing to retire later than age $t_{R}$ (the NRA) could be allowed to use their PAAW payouts in the years immediately following $t_{R}$ to purchase additional PAAWs, and those wishing to retire earlier than age $t_{R}$ could be allowed to sell some of their PAAWs to 
provide retirement income during the years prior to $t_{R}$. These transactions could occur at pre-specified prices (to correspond to the current system) or at market prices.

\section{The assignment of property rights to accrued benefits}

Under the current system, workers' future social security benefits are not protected with formal legal property rights. Congress can alter benefits, without regard to whether they have been implicitly accrued under the current system. ${ }^{16}$ Our approach would formally split future benefits into those accrued to date, and those yet to be accrued, giving property rights, and reduced political risk, to the former but not to the latter. Workers would get periodic social security statements telling them their balance of PAAWs and their market value (assuming that there is a market for PAAWs, as we discuss below) This treatment would enhance the ability of individuals to plan for their retirement. It would also correspond more closely to the legal treatment of private and state and local defined benefit pension plans. ${ }^{17}$

The assignment of property rights at the individual level leads to a natural choice of accounting method for the system as a whole: accrual accounting. Under this method, the present value of new accruals would be reported directly on the income statement of social security. This would make the present value costs of a legislative increase in social security benefits much more transparent than under the current system (see Jackson, 2004, for a discussion of this and other advantages of accrual accounting). As we describe later in the paper, the development of a liquid market in PAAWs would take this one step further by allowing the government to report the market value of new accruals (as opposed to an actuarial estimate of present value).

Assigning property rights to accrued benefits has potential disadvantages as well. In particular, it reduces the flexibility that future Congresses have to reduce

\footnotetext{
${ }^{16}$ The 1935 Social Security Act stated "The right to alter, amend, or repeal any provision of this Act is hereby reserved to the Congress." The right of Congress to reduce or eliminate benefits that are scheduled to be paid as a result of previous Social Security contributions was re-affirmed by the 1960 Supreme Court decision on Fleming v. Nestor. See http://www.socialsecurity.gov/history/nestor.html for further details.

${ }^{17}$ As in the current system, we would forbid the use of PAAWs held by workers in their private social security accounts as collateral for loans. This is a necessary limitation on their property rights if we intend to preserve their social security savings for their old age.
} 
benefits in response to unexpected shocks. To reduce this cost, we propose later in the paper that the system be made self-balancing on a present value basis, so that decreases in revenue and increases in system costs are automatically compensated for by decreases in accruals. We leave a full treatment of the advantages and disadvantages of assigning property rights to future work.

\section{Alternative accrual rules}

As mentioned above, there are alternative accrual rules under which the benefits of young individuals accrue less rapidly. The "fastest" accrual rule described above corresponds to the benefits an individual would end up with in the current system if he never worked again. For some purposes, such as considering a transition to a completely new system, this accrual rule may be overly generous. Young workers, even with maximal covered wages, accrue large numbers of PAAWs per contribution, because their accrual is equivalent to a poor worker who had steadily earned very low relative wages all through his life. A worker whose average relative wage for the first $\mathrm{s}$ years is $w$ would accrue $f((w \cdot s) / 35)=f(w \cdot(s / 35))$ PAAWs by the end of $s$ years, where $f$ is the initial relative benefits function, exactly equal to a worker who earned smaller relative wages of $\mathrm{w} \cdot(\mathrm{s} / 35)$ per year but worked all 35 years. We therefore consider a second accrual rule that we see as a natural alternative.

Instead of taking the sum of relative wages to date and dividing by 35 , compute the average relative earnings to date, put this value into the initial relative benefits formula, and then pro-rate the benefits by the fraction of years worked to date (based on an assumed 35 year work life). A worker whose average relative wage for the first $s$ years is $w$ would then accrue $f(w) \cdot(s / 35)$ PAAWs by the end of these years. Since $f$ is concave, with $f(0)=0$, this second accrual is always smaller than the first, $f(w) \cdot(s / 35) \leq$ $\mathrm{f}(\mathrm{w} \cdot \mathrm{s} / 35)$ for all $0 \leq \mathrm{t} \leq 35$. Figure 6 shows the accruals by age under each rule for a hypothetical worker who always earns relative wages of 1.75 for the 35 years between the ages of 20 and 55.

The second accrual method has the great advantage of not treating high wage young people as if they were poor. Also, as shown in Figure 6, a worker who earned a steady relative wage all his life would accrue the same number of additional PAAWs 
each year, moving up the straight line. For this reason we refer to this method as the "straight-line" accrual rule.

This straight-line accrual method closely resembles that used by the Social Security Board of Trustees to calculate the maximum transition cost measure of unfunded obligations. ${ }^{18}$ The maximum transition cost measure is also the basis for Jackson's (2004) analysis of accrual accounting.

\section{PAAWs vs. notional accounts}

A growing number of countries, most notably Sweden, Italy, and Poland, have recast their social security systems as notional accounts. Participants in these systems make contributions to "notional" accounts, and the balances are legislated to earn an interest rate that is generally set as a function of wage growth. At retirement, balances are converted to a life annuity, based on cohort survival probabilities. These accounts are called "notional" because balances do not correspond to any underlying assets and returns are not those of a financial instrument. Notional accounts are by construction partially self-balancing (see Valdes-Prieto, 2000, and Auerbach and Lee, 2006).

While PAAWs are similar in some ways to notional accounts, we think progressive personal accounts would represent a significant advance. First, since PAAW accrual is based on a redistributive, concave formula (modeled on the current system), progressive personal accounts would retain the intra-generational risk sharing / redistribution of the current system, whereas notional accounts as typically implemented do not. Second, and more fundamentally, since PAAWs are bona fide securities, they can be traded (as we will describe more clearly in the next section). In our view, a balance should always correspond to market value and returns should correspond to market returns. Market price, not notional balance, conveys useful information to account owners and to the stewards of the social security system.

\footnotetext{
${ }^{18}$ The maximum transition cost measure of unfunded obligations equals the present value of accrued Social Security benefits payable after the current date, minus the present value of taxes on future benefits minus the value of the Trust Fund. Accrued benefits of participants who are currently working are calculated in the same manner as disability benefits (Goss, 1999), but then prorated by (age - 22) / 40 (see SSA, 2007). Benefit calculations for the maximum transition cost measure exclude the lowest $n$ years of relative earnings, where $n$ equals the whole-number portion of $\min (5$, years_worked $/ 5)$. Our accrual rule is based on the highest 35 years of relative earnings, with no exclusions allowed if there are fewer than 35 years worked.
} 


\section{Trading PAAWs}

So far we have not allowed PAAWs to be traded or priced, and we have replicated the current DB system, including its intra and inter-generational risk sharing, with a system of progressive personal accounts. This has the advantage over the current system of bestowing property rights over benefits as workers accrue them, meeting one of the goals of the Republican push to reform Social Security. The PAAWs will also make the accrual of future benefits very transparent, in contrast to the opaqueness of the current system.

The trading of PAAWs from individual accounts is a step that need not be taken. But if implemented in a measured way, it could provide further advantages.

\section{A. The benefits of a market for PAAWs}

The market price for PAAWs would provide important information to households, governments, and other market participants. First, a market price for pooled PAAWs would give people information about the market value of their own PAAWs, helping them with their financial planning decisions regarding saving and asset allocation. Second, a market value would make it more difficult for the government to take them, thus further enhancing property rights. Third, the price of PAAWs would allow households to compare the value of their tax contributions with the value of their accrued assets. Fourth, the price of PAAWs would give economists a reliable guide to the present value of the benefits promised by the social security system, a number that is currently quite controversial. It would also help in designing policies that make the system self-balancing. Fifth, the trading and pricing of PAAWs would enable the private sector to play a more significant role in social security, as we shall see. Sixth, as the pools of PAAWs mature, they turn into pools of individual annuities. As such, they become a form of survivor or longevity bond that provide a market guide to aggregate mortality probabilities.

There is another big indirect benefit from trading PAAWs. The social security system embodies a gigantic contingent obligation from the government. The economic system would be improved if a fraction of these obligations could be securitized and 
priced and made available as collateral for other obligations. PAAWs could be used as collateral for issuing further annuities. We believe this would have a salutary effect on the annuities markets and the reverse mortgage markets, which at the moment are hobbled by inefficiencies and adverse selection.

Until a few years ago, financial markets may not have been able to process these new securities. But given the recent advances in structured finance, Wall Street should now be ready for them.

\section{B. Implementing the trade of PAAWs via pools}

One way to ensure volume in the trading and pricing of PAAWs would be to require owners of the personal accounts to sell a fixed percentage of their new PAAWs each year and purchase other securities with the proceeds. Workers would not be allowed to spend the proceeds prior to retirement, nor would they be allowed to use balances in their social security accounts (PAAWs or other securities) as collateral for loans. They could either be required to purchase a specific basket of securities (for example a broad-based equity index fund) or allowed to choose the securities or baskets of securities that they wished to hold in their accounts.

As discussed above, portfolio choice is a dimension along which Democrats and Republicans typically disagree. Republicans see choice as beneficial, while Democrats see it as dangerous. Here, a compromise is conceptually easy to work out; one simply restricts the degree of choice available within personal accounts. By keeping the percentage of PAAWs sold each year to be rather low (say at $10 \%$ ), personal account holders would not be able to put the bulk of their social security benefits at risk.

An alternative approach would be for individuals to retain $100 \%$ of their PAAWs, but for the government to issue extra individual PAAWs in proportion to those accrued that year, and to sell these PAAWs directly to pools in financial markets. The government could use the proceeds of the sale to retire other, more traditional, forms of debt. Under this approach, the payouts from individual's accounts would continue to mimic those promised by the current system.

PAAWs (and PANTs) are individual-specific securities, paying as long as the individual lives, so trading them presents many liquidity and adverse selection 
problems. They are thus analogous to individual mortgages, whose payments depend on the individual's decision to prepay or default (in which case the payoff also depends on the individual's home resale value). In the mortgage market these problems have been overcome by the pooling of securities, and that is what we propose for PAAWs. To be marketed efficiently, PAAWs should be pooled, just like mortgages. Investors in the pool would not buy a single PAAW, but a pro rata share of all the PAAWs in the pool. ${ }^{19}$

Let us denote by Pool $\left(t, t_{R}\right)$ the collection of all PAAWs issued in year $t$ to workers whose statutory retirement year is $t_{R}$. This pool of PAAWs would consist of PAAWs $\left(i, t_{R}\right)$ issued to over 3 million workers $i$. The prediction of PAAW payments for any one worker $\mathrm{i}$ is fraught with uncertainty; but the pool is much less uncertain in percentage terms.

Assume for now that the personal account owners would be required to sell exactly the $10 \%$ of their newly accrued PAAWs we spoke of above. These would be gathered into Pool $\left(t, t_{R}\right)$, and then shares would be sold off to investors, exactly as in the mortgage market. A single price $\Pi_{t}\left(t, t_{R}\right)$ per PAAW would emerge for each pool, even though the individual PAAWs ( $i, t_{R}$ ) would pay off differently, depending on the idiosyncratic mortality of individual i. In the mortgage market, different homeowners, with different propensities to prepay or to default, sell their individual specific promises into pools. Shares in these pools are sold to the public. Investors are enabled to hold liquid shares, and they need only predict the average default rates or prepayment rates for the pools, not individual specific rates. The same would be true of pools of PAAWs. Investors would only need to predict average mortality rates, for example. The shares could be resold later at any time $s>t$ for price $\pi_{s}\left(t, t_{R}\right)$.

Once $s \geq t_{R}$, the pool of PAAWs effectively becomes a pool of PANTs. These pooled PANTs would be a form of survivor or longevity bond. ${ }^{20}$ The current annuities market is so hobbled by adverse selection and thin markets that it is hard to obtain a

\footnotetext{
${ }^{19}$ Rather than pooling all individuals together, one could imagine creating separate pools for men and women. All else equal, the price of the pool of women's PAAWs would be higher, due to women's higher life expectancy. To offset this, the government would likely want to set higher match rates for women.

${ }^{20}$ For more on survivor or longevity bonds, see, e.g., Blake and Burrows (2001) and the literature that followed.
} 
market forecast about longevity. The gigantic mandatory saving plan created by social security provides a remarkable opportunity to improve this situation. The prices of the pools of PAAWs and PANTs would be an invaluable guide to private companies wishing to issue their own annuities, or reverse mortgages, making those markets more efficient. It would also provide information about longevity to private firms with defined benefit pension obligations. Annuity providers and DB pensions could hedge their exposure to longevity risk by holding shares of pooled PANTs.

\section{The private sector}

Until now, we have imagined PAAWs as securities issued by the government to individuals, with a fraction tradeable in pools among the general public. But it is also possible that the private sector could issue a significant fraction, or even all, of the PAAWs. A firm issuing $x \%$ of the total PAAWs $P\left(t, t_{R}\right)$ awarded in year $t$ to workers reaching retirement age in year $t_{R}$ would be responsible for delivering $x \%$ of the benefits called for by that pool. ${ }^{21}$ Firms would compete with each other, offering to take on the PAAW liabilities for the lowest price per PAAW. For every $s \geq t$ they would be required to keep a margin collateralizing their obligations, based on the price $\pi_{s}\left(t, t_{R}\right)$ of the tradable government PAAWs of the same vintage. Workers would receive PAAWs from the government and from private firms, but would only be allowed to sell the government issued PAAWs. ${ }^{22}$ The collateral requirement should guarantee that the privately issued PAAWs are just as secure as the government PAAWs. One could further imagine creating a second pool PrivatePool $\left(t, t_{R}\right)$ of privately issued and tradable PAAWs in addition to the pool Pool $\left(t, t_{R}\right)$ of PAAWs issued by the government.

\footnotetext{
${ }^{21}$ One complication is that a firm would have to rely on the government to inform it when workers in the pool died. Information about deaths is also a requirement (and also sometimes a problem) for the current social security system.

${ }^{22}$ To insure the safety of payments to retirees, the government should be held responsible for making any payments the private sector failed to make. This would provide the government with the incentive to set strong funding and collateral requirements.
} 


\section{Pricing PAAWs}

To determine what the market price of a PAAW would be if it were traded, we will need to introduce a model. ${ }^{23}$ We first examine the simplest model: one that assumes risk neutrality. We then sketch out the beginnings of how one might construct a model to compute pricing under risk aversion, leaving the implementation of this for ongoing work.

\section{A. Pricing PAAWs assuming risk neutrality}

Under risk neutrality, the value of an individual PAAW depends on assessments of 1 ) the growth in average wages, 2) the future path of interest rates, 3) individual survival probabilities. For our calculations below, we assume a long-run growth in average real wages of $1.1 \%$ and a long-run real interest rate of $3 \% .{ }^{24}$ We use the cohort life tables from Bell and Miller (2002) and assume for now that all individuals of the same age face the same conditional survival probabilities ${ }^{25}$, i.e. that there is no heterogeneity or private information about these probabilities. ${ }^{26}$ Finally we make the assumption that the individuals are fully rational and have the correct expectations of the average wage growth rate.

Based on these assumptions, we compute an estimate of the market price $\pi_{s}(2000,2047)$, measured in average wage units. Figure 8 shows the estimated price of a PAAW across time (age) for individuals born in 1980, turning 20 in 2000, and hitting the statutory retirement age of 67 in 2047 . The market price of the PAAW, in date s average wage units, rises steadily as $s$ approaches $t_{R}$, because a) the probability of reaching the retirement age increases as any individual survives an additional year and

\footnotetext{
${ }^{23}$ Of course, once the market is thriving, one could simply observe market prices. But this still begs the question of how market participants would price PAAWs.

${ }^{24}$ These equal the intermediate cost assumptions in the 2005 Social Security Trustees Report. The assumptions in the 2008 Trustees Report are virtually the same: growth in average real wages of $1.1 \%$ and real interest rate of $2.9 \%$.

${ }^{25}$ For the calculations presented, we used the survival probabilities for males born in 1980.

${ }^{26}$ With heterogeneity in survival probabilities, the price of a representative pool of PAAWs would not give a perfect signal to individuals about the market value of their individual future retirement cash flows.
} 
b) the real interest rate is greater than the growth in average real wages, so that one year's less discounting has a bigger effect than the increasing value of a wage unit.

Next, for each of the four representative workers, we compute (see Figure 9) the total projected market value of accrued PAAWs (measured in contemporaneous average wage units); i.e., the product of PAAW balances at any date $s$ and the price at date $s$ of a PAAW $\pi_{s}(2000,2047) .{ }^{27}$ These rise over time, for example to a value of 6.7 for the cohort average worker, meaning that the value of accrued balances at retirement is expected to be 6.7 times average economy-wide wages.

\section{B. Allowing for risk aversion}

Pricing PAAWs by assuming risk neutrality could easily be misleading. In ongoing work (Geanakoplos and Zeldes, 2008), we are examining model-based pricing allowing for risk aversion. If PAAWs were a redundant security (i.e. the payoffs could be perfectly replicated by holding a basket of other traded securities), this would be a relatively straightforward task. For example, if the cash flows were always equal to the cash flows stemming from a certain number of shares of the S\&P 500 , plus a certain number of TIPS (Treasury Inflation Protected Securities), then one could simply price PAAWs by looking at the market price of the shares of the S\&P 500 and the investment needed to acquire the TIPS. Of course it is not possible to perfectly replicate PAAWs with securities that are currently marketed. An alternative approach (followed in Geanakoplos and Zeldes, 2008) is to project the return on PAAWs onto the returns of currently traded securities and assume that the residual has price equal to zero.

Goetzmann (2005) found that wage growth and stock returns are uncorrelated, or even slightly negatively correlated, over short periods of time. He concluded that stocks would not figure much in a replicating portfolio for wage-indexed liabilities. While this might be true for wage-indexed securities with very short maturities, this would not be so for wage-indexed securities with long maturities. Common sense suggests that over the long run real wages and stock returns must be positively correlated. For example, a permanent drop in future productivity would likely lead to both lower future real wages

${ }^{27}$ Since we assumed that all workers have the same mortality, it follows that the prices of all accumulated PAAWs are the same, $\pi_{s}(t, 2047)=\pi_{s}(2000,2047)$ for all $2000 \leq t \leq s$. 
and a lower future value of the stock market, compared to what they would have been otherwise. It is perfectly consistent that a rise in stock returns today does not signal a higher wage today, yet does make it more likely that wages in 30 years will be higher. Thus stocks would almost surely have a significant positive weight in the replicating portfolio at time $t$ for PAAWs indexed to wages at time $t_{R}$ much greater than $t$. As $t$ approaches $t_{R}$, the replicating portfolio would change and stocks would drop out. In Geanakoplos and Zeldes (2008) we model this long run correlation, and use Monte Carlo derivative pricing methods to estimate the price of a PAAW. ${ }^{28}$

An alternative approach to pricing PAAWs directly would be to first estimate the prices of the two underlying securities - Average Wage Securities and pools of PANTs, and then use these to price the composite PAAWs. There is a literature in financial theory indicating how, under certain conditions, it is possible to dynamically trade the portfolios of two securities to replicate the product of the securities. ${ }^{29}$ We could apply this approach to obtain the price of PAAWs as a function of the prices of average wage bonds and pools of PANTs.

If the best replicating portfolio of currently traded securities leaves a residual that cannot be assumed to have price zero, then one has to use an alternative asset pricing model to assess the value of the residual. There are several models available for this purpose, and one would need to check that the price of the residual is robust, or at least that upper and lower bounds could be sensibly computed. We leave this for future work.

\section{Risk and return of PAAWs}

As just discussed, in the long run wage growth is correlated with stock market growth. Hence if PAAWs are priced in the market, they must offer equity-like returns in the long run. ${ }^{30}$ But as workers age, and $t$ approaches $t_{R}$, PAAW volatility becomes very

\footnotetext{
${ }^{28}$ This follows the work of Lucas and Zeldes (2006), who use this type of approach to estimate the market value of private defined-benefit pension liabilities (PBO measures).

${ }^{29}$ Amin and Bodurtha (1995) show how to price certain types of "quantos": contingent claims with a "quantity" or nominal cash flow determined by equity values in one currency but paid in another currency at a fixed rate. For example, the value of a first security, such as the Nikkei stock index, might determine the number of units of a second security, such as the U.S. dollar, that must be paid.

${ }^{30}$ This is consistent with Geanakoplos, Mitchell and Zeldes (1998). Equity-like returns are a feature of PAAWs securities, but not necessarily of Social Security as a whole. Achieving equity-like (or any market) returns for all of Social Security would first require eliminating its legacy debt, for example by
} 
low. For example, when $t=t_{R}-1$, the only payoff uncertainty is over what next year's real wage will be. All future payoffs are determined by that same number, and by aggregate mortality. By contrast, even if investors can be fairly confident of next year's dividends, they will be very uncertain about dividends in 10 years, and stock prices at $t_{R}$ are quite uncertain at $t=t_{R}-1$. If personal accounts hold only PAAWs, it will never happen that two different cohorts retiring one year apart will get $20 \%$ different retirement benefits, as could easily happen if investors kept their money in stocks and sold them for annuities at retirement. PAAWs might thus turn out to be a more attractive investment vehicle than stocks for individuals planning for retirement.

\section{The government match rate (under risk neutrality)}

Once PAAWs are priced, in any of the ways indicated above, we can compute the government "match" under the current social security system (which can be positive or negative, i.e. a subsidy or a tax) as the difference between the market value of PAAWs received and the value of the contribution. The average match rate is defined as $\left[\pi_{t}\left(t, t_{R}\right) *(\triangle P B A L) /\right.$ annual contribution] -1 and captures the percentage by which the social security system is subsidizing (or taxing if negative) account contributions in each year. The marginal match rate is defined as $\left[\pi_{t}\left(t, t_{R}\right){ }^{*}\right.$ (increment to PBAL per additional dollar of contribution)] -1 , i.e. the percent subsidy (or tax) for a marginal additional account contribution. The match rate of course depends on which accrual rule (fastest or straight line) we use.

Unlike most simple DC plans, the match rate is not constant across people or time. It depends on PBAL, the price of a PAAW, and the fraction of a contribution that "counts". The match rate can be positive or negative, but it can never be $<-100 \%$ (i.e. balances cannot be taken away). Note that all of the redistribution related to these accounts occurs on the way in (i.e. as contributions are made); none of it occurs while funds are earning returns or when they are withdrawn.

Figures 10 and 11 show the average match rate and the marginal match rate, under the fastest accrual rule, for our representative workers, taking the price of PAAWs 
derived earlier from our risk neutral model. For the first 35 years of work, the average and marginal match rates are identical, with the exception of those rare years containing bend points. On average over the life-cycle, the match rates are quite negative. This corresponds to the fact that the current system is primarily unfunded; current and future workers are paying for the benefits given to the initial generations starting in the 1940s who had not contributed much before getting benefits. Rather than getting low returns, as they would under the current system, workers receive negative matches on their contributions and then receive market rates of return on balances in their accounts. ${ }^{31}$ The match rates are positive for young workers and negative for middle-aged and old workers. The average match rate is lower for the old for two reasons. First, under the rapid accrual rule, a given relative wage contribution generates less PAAWs the higher is PBAL, and PBAL rises with age, as we saw in Figure 3. Second, the 35-year averaging formula means that earnings in the 36th year and beyond accrue PAAWs only by the amount they exceed the 35th highest relative wage to date, so that an extra year of work generates fewer additional PAAWs than it would if the worker had not yet worked 35 years. (This second effect is not relevant for the marginal match rate in Figure 11, because relative wages in later years are greater than or equal to the $35^{\text {th }}$ highest, so that an extra hour of work generates the full PAAWs increment.) These factors are only partially offset by the fact that, as we saw in Figure 8 , the price of a PAAW rises with age.

We agree with our discussant Jason Furman that it would be desirable for our match rate to inform each worker directly and simply about his incentives to work. Feldstein and Samwick (1992) estimated the implicit tax rate on labor income (or the extent of the work disincentive) due to the U.S. Social Security system, i.e. the difference between the incremental contribution and the present value of the incremental lifetime benefits due to a dollar increase in current income. ${ }^{32}$ They found it

\footnotetext{
${ }^{31}$ Consistent with Geanakoplos, Mitchell, and Zeldes (1998), this negative match combined with market returns corresponds to the lower-than-market rate of return received overall under the current system. ${ }^{32}$ When earnings are stochastic, as opposed to deterministic, computing the incentive to work becomes much more complicated, because one needs to incorporate the different possible earnings paths, and the slope of the benefit schedule and the marginal utility of consumption under each path. The Feldstein and Samwick calculations of the lifetime marginal tax rate of social security do not incorporate this uncertainty
} 
to be much higher for the young than for the old. ${ }^{33}$ This might seem to contradict our generally declining marginal match rates in Figure 11 (a positive match corresponds to a negative tax), but this is not the case, because the marginal match rates in Figure 11 do not give an accurate guide to the implicit marginal tax rate on labor income. Workers who want an accurate assessment of the incentive to work under the fastest accrual rule must make a more complicated dynamic calculation. Earning more when young may accrue many PAAWs (which the match rate reveals), but the resulting increase in PBAL lowers future match rates. Hence for young workers the true incentive to work is much lower than the marginal match rate in Figure 11 suggests. ${ }^{34}$

Under the assumption that relative wages do not vary too much over a worker's lifetime, the marginal match rate from our second accrual method - the "straight-line method" - is proportional to the implicit marginal tax rate on labor due to social security. ${ }^{35}$ The marginal match rate under the straight line method therefore conveys the correct incentive to work, without requiring any dynamic adjustment. Workers' account statements could include either the value of the marginal match rate directly or the inputs needed to compute it. The greater correspondence under this second accrual method between the match rate and the incentive to work represents an additional advantage of using the "straight-line" accrual instead of the "fastest" accrual method.

Figure 12 and 13 show the average and marginal match rates under this straightline accrual method, and compares them to those under the fastest accrual method. A worker with constant relative earnings (such as worker 1) will get the same PAAW allocation per relative wage contribution all through his life (recall figure 6). Since

\footnotetext{
- their calculations simply assume that workers will end up on a specific segment of the PIA schedule with certainty

${ }^{33}$ Cushing (2005) showed that the decline largely disappears once one takes into account disability and survivor benefits.

${ }^{34}$ We are grateful to Jason Furman for bringing the importance of this issue to our attention, thereby directing our focus toward the "straight line" accrual rule.

${ }^{35}$ Formally, the worker's average relative earnings to date must put the worker in the same bracket (the range across which the slope in figure $1 \mathrm{~b}$ is constant) as his average relative earnings at the end of his career. Under this assumption, the implicit marginal tax rate from social security equals -1 times the marginal match rate from the straight line method times the social security contribution rate. Note that the
} 
PAAW values rise as a worker ages (and survives), the match rate is steadily increasing for this worker, i.e. a worker who always earns the same relative wage will have increasing incentive to work an extra hour as he gets older. ${ }^{36}$ The average match rate for the economy wide average worker starts out around negative $40 \%$, meaning that for every dollar of contributions he gets 60 cents of benefits. Since contributions are about $10 \%$ of wages, this means he faces an average tax rate on wages of around $4 \%$. Since the system is progressive, his marginal tax rate is higher than his average tax rate. As the worker ages, the tax eventually turns into a slight subsidy.

\section{Incorporating budget balance mechanisms into Progressive Personal}

\section{Accounts}

In this section, we show that our proposed system can be modified to incorporate a market-based aggregate self-correction mechanism. There is a variety of ways to do this. Here we focus on one in particular, in which we balance the system "on the way in", meaning that in any year the aggregate quantity of newly-issued PAAWs is set such that their market value equals the aggregate value of new contributions. Assuming that we start with an initially balanced system (and we describe possible ways to transition to this), then the government should be able to optimally manage its portfolio to hedge its exposure and maintain balance "on the way out" as well.

\section{A. Transition}

The first step is to recognize that in a pay-as-you-go system, the early generations are given a huge windfall transfer. Retirees in the 1940s collected Social Security benefits even though they hardly made any contributions. Similarly, retirees in the 1950s collected benefits even though they had only contributed for 10 or 15 years, and so on. ${ }^{37}$ In a pay-as-you go system, current and future generations of workers are

\footnotetext{
marginal incentive to work is the same under both accrual methods (while the marginal match rate is not). 36 The assumption in the previous footnote holds for workers 1 and 3 in Figure 13 , and thus the marginal match rate under this accrual method exactly captures the true incentive to work. For workers 2 and 4 , final average earnings turn out to be sufficiently higher than cumulative average earnings when young, to put workers in a higher Figure $1 \mathrm{~b}$ bracket than is used for computing the contemporaneous match rate. In this case, the annual match rate when young does not correspond to the incentive to work.
}

${ }^{37}$ See Geanakoplos, Mitchell, and Zeldes (1999) 
called upon to pay off those transfers. But why should this debt overhang be borne by those least able to pay?

One approach would be to move rapidly to a new system by issuing "recognition PAAWs" to current workers and retirees to compensate for (i.e. recognize) past social security contributions. These would be obligations of the United States government, and not of future social security contributors. Goss, Wade, and Schultz (2008) calculate that the "maximum transition cost" (as of the beginning of 2007) would be $\$ 16.7$ trillion. Ignoring risk adjustments, this provides an estimate of the market value of the required recognition PAAWs. There is no reason that the burden of this debt, created by the transfers to the early generations of Social Security beneficiaries, should be apportioned based solely on "covered" labor earnings. Payments of interest and principal on the recognition bonds would therefore come both from issuing new debt (i.e. rolling some of it over) and from taxes on all income, including labor income above the social security earnings cap and capital income. Using a back-of-the envelope calculation, we estimate that this burden would amount to about a 1 percentage point increase in the tax rates on personal income and corporate profits in perpetuity. ${ }^{38}$

Because the current system does not legally ensure property rights on accrued benefits, it might also be appropriate to give workers fewer recognition PAAWs than would be implied by the accrual rule chosen for new contributions. By making this reduction for current generations, the government would reduce the future tax rates it would have to levy on future generations. There is a compelling case for such a reduction. The current system of taxes and legislated benefits is not in fiscal balance, and the shortfall has to be borne by somebody. There seems no reason to exclude the current generations from bearing any of these costs. Under our plan future workers would have to pay a tax on the order of $1 \%$, or about $10 \%$ above their normal social

\footnotetext{
${ }^{38}$ To obtain this estimate, we solve for the perpetual tax on personal income and profits that would be equal in present value to $\$ 16.7$ trillion, the SSA Office of Actuary's estimate of the 2007 "maximum transition cost" measure of unfunded obligations (UO). In formula, we need to solve for $t$ such that $(t$ * $Y$ ) $/(\mathrm{r}-\mathrm{g})=\$ 16.7$ trillion, where $\mathrm{t}$ is the tax rate, $\mathrm{r}$ is the real interest rate, and $\mathrm{g}$ is the growth rate of income (GDP). This implies that $\mathrm{t}=(\mathrm{UO} / \mathrm{Y})^{\star}(\mathrm{r}-\mathrm{g})$. Based on the $2008 \mathrm{OASDI}$ Trustees Report long-term forecast, we assume a constant future real interest rate of $2.9 \%$ and future real income growth of $2.1 \%$. Given combined 2007 personal income and corporate profits of about $\$ 13.3$ trillion, our assumptions imply a tax burden of $1 \%$. Note that these calculations do not incorporate any risk adjustment of the sort proposed in Geanakoplos and Zeldes (2008).
} 
security tax. It seems fair to ask the current generations to accept a $10 \%$ reduction in their social security benefits, especially since we will be locking in property rights to these benefits. If we thought current benefits were still too large, or that the resulting tax in perpetuity was still too high, we could reduce these benefits even more.

\section{B. A fully funded social security system}

Once this debt overhang is taken out of the social security system, there is no reason the system cannot operate in fiscal balance going forward, as a fully funded ("pre-funded") system. We are thus led to propose a modification of the current benefits rules which has the virtue of balancing the system "on the way in". While the government match under a system that maintains "balance on the way in" will by necessity alter the redistribution / risk sharing of the current system, we propose to keep such changes to a minimum.

On average, the present value of the social security contributions a cohort makes under the current system is slightly greater than the present value of the benefits mandated by current law. Thus workers could be made to buy their benefits via their contributions without having to increase contributions or reduce future benefits. We propose modifying the accrual rules, so that in every year the market value of PAAWs awarded is just equal to the market value of all social security tax contributions. This aspect is similar to what occurs with standard defined contribution accounts.

There are many ways to structure the government match such that the overall budget balances on the way in. Here we focus on one simple possibility. For each year $t$ let the preliminary allocation of PAAWs be established exactly as in the current system described in the previous section, say under the straight-line method of accrual. Compute the total market value of this allocation in the PAAWs markets. Next, define $\lambda_{t}$ as the ratio of total annual tax contributions in $t$ to the market value of the preliminary PAAW allocation above. The final allocation of PAAWs is set by multiplying the preliminary allocation by $\lambda_{t}$. This will result in an allocation of PAAWs that exactly balances the budget. The government match will then be the difference for each individual between the value of his final allocation of PAAWs and his tax contribution. 
Once the legacy tax is taken out and the PAAWs are scaled up to equal current contributions, the government match rate looks much more generous. In Figures 14 and 15 we display the average and marginal government match rates (respectively) that incorporate this budget balancing (for each accrual rule) for each of our four representative workers. Values for $\lambda_{t}$ are calculated using the assumption that the cross-sectional age-income profile is flat (panel 1) or equivalent to the cohort-average time profile (panels 2-4.) Figure 14 shows that average match rates are generally above zero for the cohort average worker under straight-line accrual. Note in Figure 15 that, for straight-line accrual, marginal match rates are (weakly) less than average match rates, and typically below zero for all but low earners. ${ }^{39}$

This revised budget balance system will be similar to the current system, but it cannot replicate it exactly. For example, we noted that the aggregate accruals in any year of the current system are independent of the aggregate contributions during that year. In the budget balance system, the aggregate accruals would move dollar for dollar with contributions.

Another difference is that in this revised system, the quantity of PAAW accruals in a year depends on the market price of PAAWs in that year, whereas in the current system it does not. In the current system, the number of PAAWs a worker gets is independent of interest rates. In the budget balance system, when long run interest rates fall relative to the long run expected growth in wages, PAAW prices will rise, and workers will therefore get fewer PAAWs. ${ }^{40}$

\section{Maintaining balance through hedging}

Since PAAWs promise future payments that are uncertain as of the time they are issued, their eventual value may diverge from their original price. Thus a system in balance on the way in may fall out of balance later. So we suggest that there is a need for a hedging entity to keep the system in balance. One possibility is to create a

\footnotetext{
${ }^{39}$ The wedge between marginal and average match rates exists because workers earn additional benefits each year even if they have no additional earnings, which boosts the average match rate but not the marginal match rate. This wedge will exist for "straight-line" accrual with any concave benefit schedule.

${ }^{40}$ A complete analysis of intergenerational risk sharing would have to take into account interest rate risk in addition to wage risk.
} 
government agency with this responsibility. Another complementary possibility would be to involve the private sector in issuing PAAWs that would be sold to households, i.e. pay firms to take on the obligations. As described earlier, the private firms would of course need to be regulated and monitored to ensure that they fully collateralized their obligations. We leave a full description of this hedging for future work.

\section{Conclusions and future research}

We showed that it is possible to preserve the redistribution and risk sharing of the current system in a system of progressive personal accounts, clarifying the link between contributions and benefits, and at the same time enhancing the property rights of the system. Along the way, we translated the current DB system into the language of DC facilitating communication in the debate over individual accounts.

We developed a variable match approach to provide progressivity based on lifetime (rather than annual) income. This approach could also be used to modify standard personal accounts (holding traditional financial assets) or notional defined contribution accounts that have recently been adopted in a number of other countries.

We argued that it would be possible to create and trade pools of PAAWs, providing an estimate of the market value of each individual's account and opening up the possibility of allowing (limited) trade in accounts. These new markets would have an enormously beneficial impact on the current annuities and reverse mortgage markets.

We emphasized the importance of making the social security system selfbalancing by incorporating a market-based aggregate self-correction mechanism. We described one possible way to do this through "balancing on the way in" and system hedging.

This paper lays the groundwork for our ongoing and future work in this area. In Geanakoplos and Zeldes (2008), we present a model for estimating PAAW prices under risk aversion, taking into account a long-run link between aggregate labor earnings and the value of the stock market. We then use these prices to calculate the market value of aggregate outstanding U.S. Social Security benefit promises. Our resulting estimates of the "maximum transition cost" measure of system obligations are significantly lower 
than those of the Social Security administration, due to our incorporation of market risk into the discounting of future benefits.

In other work, we are trying to further improve the risk-sharing and redistribution features of our progressive personal accounts, and we are also examining alternative market-based self-correction mechanisms. We are working to spell out in more detail how our proposed market for PAAWs and related new securities would operate in practice. Finally, we hope to investigate the relevance of progressive personal accounts to private pension plans. 


\section{References}

Amin, Kaushik I. and James N. Bodurtha, Jr., 1995, "Discrete-Time Valuation of American Options with Stochastic Interest Rates," The Review of Financial Studies, Vol. 8, No. 1, (Spring), 93-234

Auerbach, Alan and Ronald Lee, 2006, "Notional Defined Contribution Pension Systems in a Stochastic Context: Design and Stability," NBER Working Paper No. 12805. December.

Bell, F.C. and M. L. Miller, 2002, "Life Tables for the United States Social Security Area 1900-2100," Actuarial Study \#116, Office of the Chief Actuary, Social Security Administration.

Blake, David, and William Burrows, 2001, "Survivor Bonds: Helping to Hedge Mortality Risk”, Journal of Risk and Insurance, 68, (2) (June): 339-348.

Bohn, Henning, 2002, "Retirement Savings in an Aging Society: A Case for Innovative Government Debt Management", in A. Auerbach and H. Herrmann, (eds.) Ageing, Financial Markets and Monetary Policy, Springer.

Borsch-Supan, Axel, 2005, "From Traditional DB to Notional DC Systems: The Pension Reform Process in Sweden, Italy, and Germany", Journal of the European Economic Association, 3 (2-3), 458-465

Clingman, Michael D., and Jeffrey L. Kunkel, 1992, "Average Wages for 1985-1990 for Indexing under the Social Security Act," Actuarial Note \#133, Office of the Chief Actuary, Social Security Administration, September.

Cushing, Matthew J., 2005, "Net Marginal Social Security Tax Rates over the Life Cycle”, National Tax Journal, 58 (2), 227-245

Donkar, Eli N., 1981, "Average Wages for Indexing under the Social Security Act and the Automatic Determinations for 1979-81" Actuarial Note, Social Security Administration, May.

Feldstein, Martin and Jeffrey Liebman, 2002, "The Distributional Effects of an Investment-Based Social Security System," in M. Feldstein and J. Liebman (eds.), Distributional Aspects of Social Security and Social Security Reform, University of Chicago Press.

Feldstein, Martin and Andrew Samwick, 1992, "Social Security Rules and Marginal Tax Rates", National Tax Journal, 45 (1), 1-22

Geanakoplos, John, Olivia Mitchell, and Stephen P. Zeldes, 1998. "Would a Privatized Social Security System Really Pay a Higher Rate of Return?" in Framing the 
Social Security Debate: Values, Politics, and Economics, edited by R. Douglas Arnold, Michael J. Graetz, and Alicia H. Munnell, National Academy of Social Insurance, Brookings Institution Press.

Geanakoplos, John, Olivia Mitchell, and Stephen P. Zeldes, 1999. "Social Security Money's Worth." in Prospects for Social Security Reform, edited by Olivia S. Mitchell, Robert J. Meyers, and Howard Young, Pension Research Council, University of Pennsylvania Press.

Geanakoplos, John, and Stephen P. Zeldes, 2008, "The Market Value of Accrued Social Security Benefits," unpublished manuscript, Columbia University, Graduate School of Business.

Goetzmann, William N., 2005, "More Social Security, Not Less," Yale ICF Working Paper No. 05-05

Goss, Stephen C., 1999, "Measuring Solvency in the Social Security System". In Prospects for Social Security Reform, edited by Olivia S. Mitchell, Robert J. Myers, and Howard Young, Pension Research Council and University of Pennsylvania Press.

Goss, Steve, Alice Wade and Jason Schultz, 2008, "Unfunded Obligation and Transition Cost for the OASDI Program" Actuarial Note \#2007.1, Office of the Chief Actuary, Social Security Administration, February.

Jackson, Howell, 2004, "Accounting for Social Security and Its Reform," Harvard Journal on Legislation, Vol 41, Number 1, Winter: 59-159.

Liebman, 2003, "Should Taxes Be Based on Lifetime Income? Vickrey Taxation Revisited," unpublished manuscript, Harvard University.

Lucas, Deborah and Stephen P. Zeldes, 2006, "Valuing and Hedging Defined Benefit Pension Obligations - The Role of Stocks Revisited," unpublished manuscript, Columbia University, Graduate School of Business.

Shiller, Robert J.,1993, Macro Markets: Creating Institutions for Managing Society's Largest Economic Risks, Oxford University Press.

Social Security Administration, Office of the Chief Actuary, 2006, "Average Wage Index", www.ssa.gov/OACT/COLA/awidevelop.html

Social Security Administration, 2007, "Online Social Security Handbook", http://www.ssa.gov/OP Home/handbook/ 
Social Security Board of Trustees, 2008, "The 2008 Annual Report of the Board of Trustees of the Federal Old-Age and Survivors Insurance and Federal Disability Insurance Trust Funds" available at www.ssa.gov/OACT/TR/TR08/

Valdes-Prieto, Salvador, 2000, "The Financial Stability of Notional Account Pensions", Scandinavian Journal of Economics, 102 (3), 395-417

Valdes-Prieto, Salvador, 2005, "Securitization of taxes implicit in PAYG pensions", Economic Policy, April, 215-265

Vickrey, William, 1947, Agenda for Progressive Taxation, The Ronald Press Company. 


\section{Mechanics of Current OASDI System}

Figure 1a

Calculation of Primary Insurance Amount (PIA)

0.70

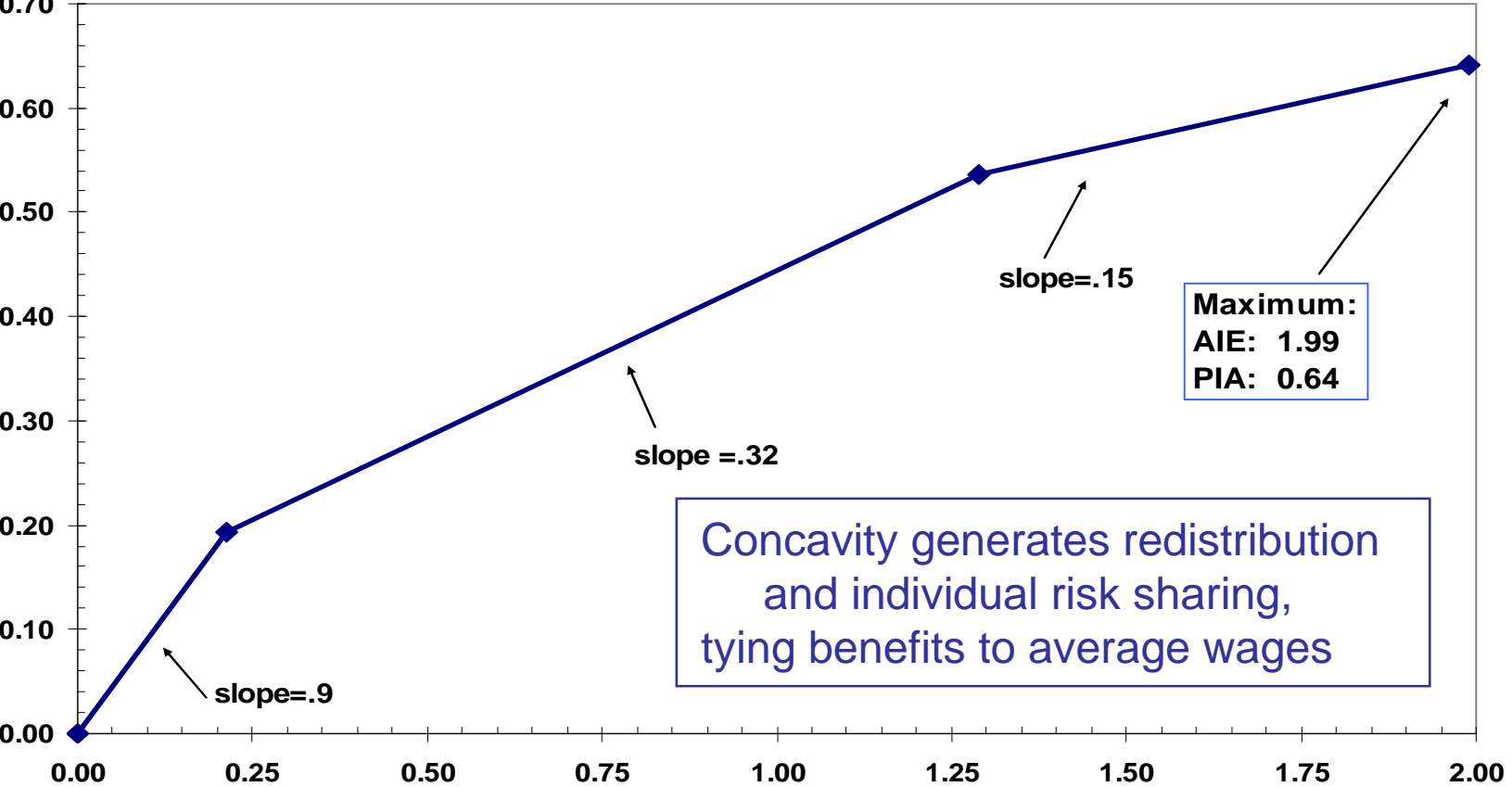

Average relative earnings (AIEl Average Wage Index)

Figure 2a

Additional Benefits per Additional Contribution (measured in average wage units)

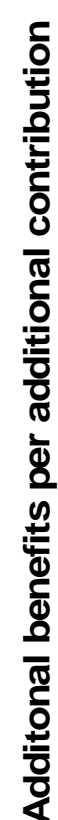

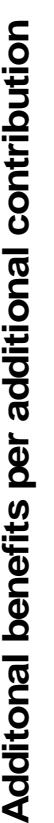
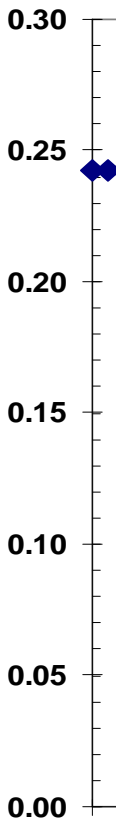


\section{Mechanics of PAAW System}

Figure 1b

Calculation of PAAWs Balance

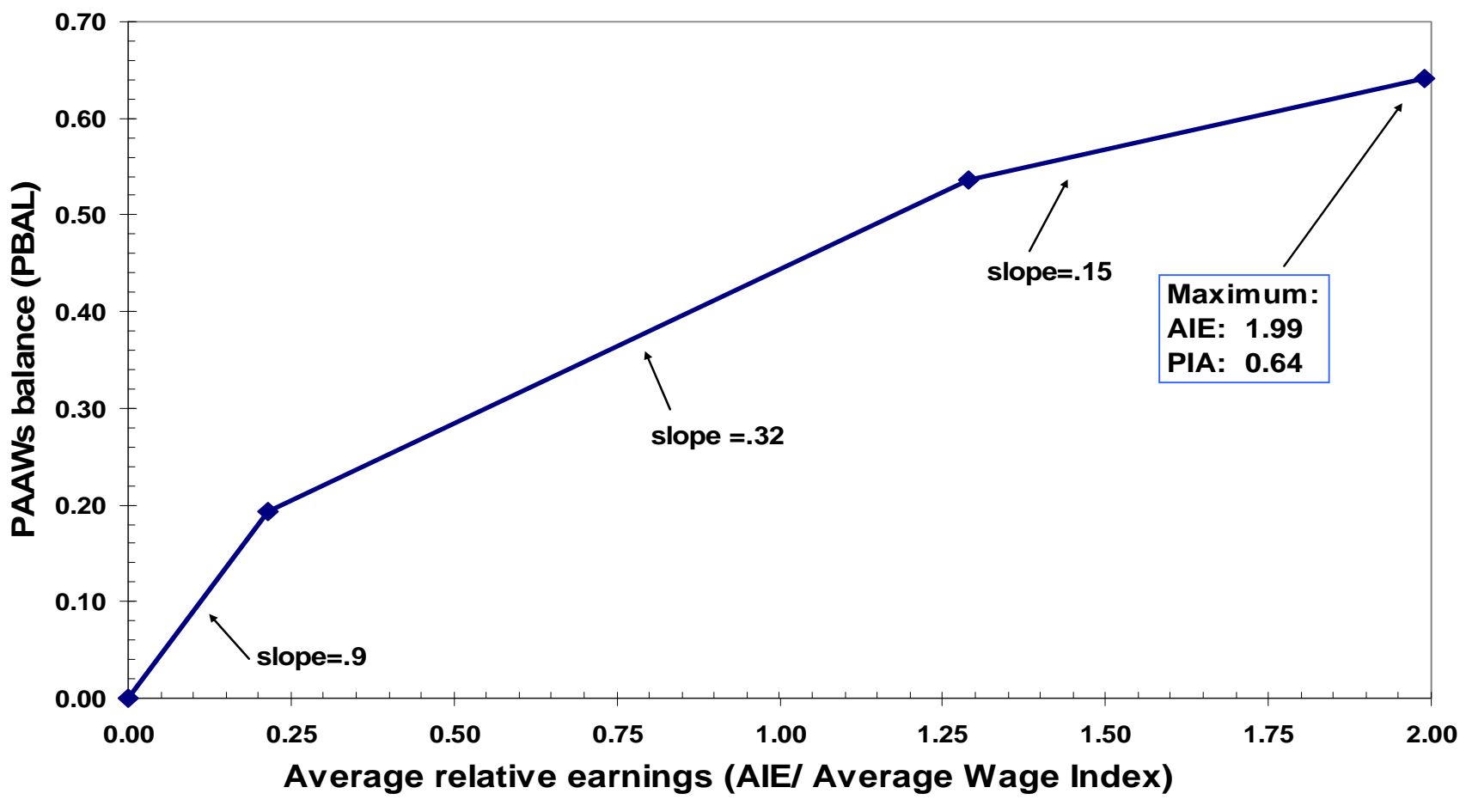

Figure 2b

Additional PAAWs per Additional Contribution (measured in average wage units)

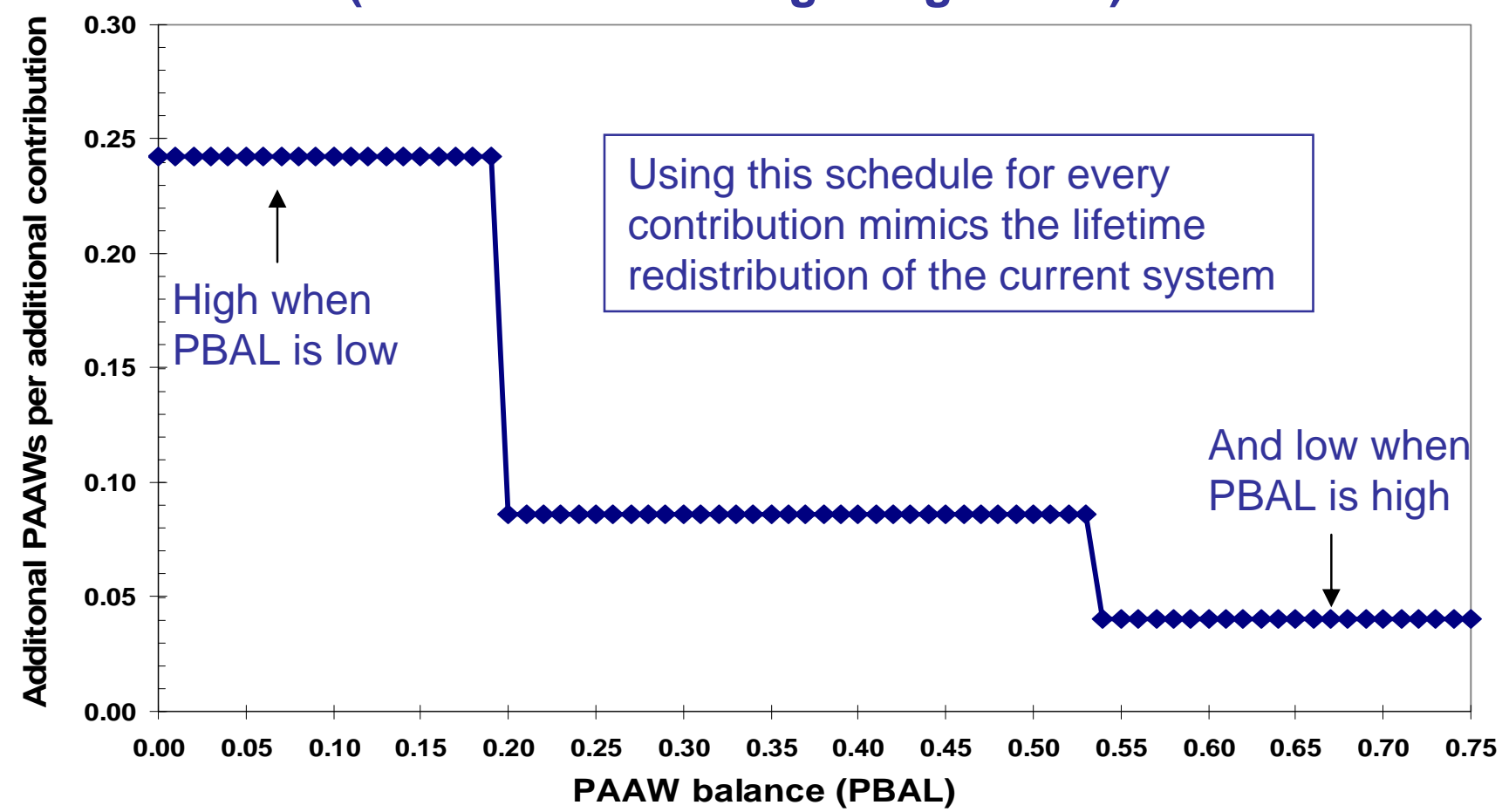




\section{Figure 3}

\section{Additional PAAWs Per Additional Contribution (measured in average wage units)}
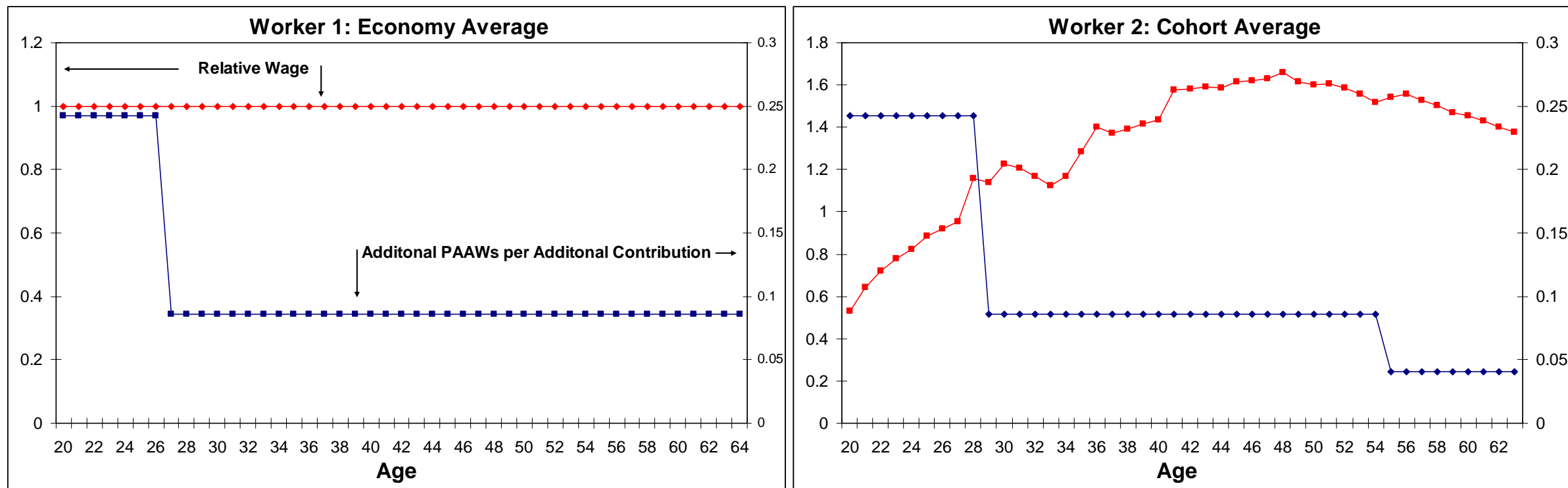

$\begin{array}{llllllllllllllllllllll}20 & 22 & 24 & 26 & 28 & 30 & 32 & 34 & 36 & 38 & 40 & 42 & 44 & 46 & 48 & 50 & 52 & 54 & 56 & 58 & 60 & 62\end{array}$ Age
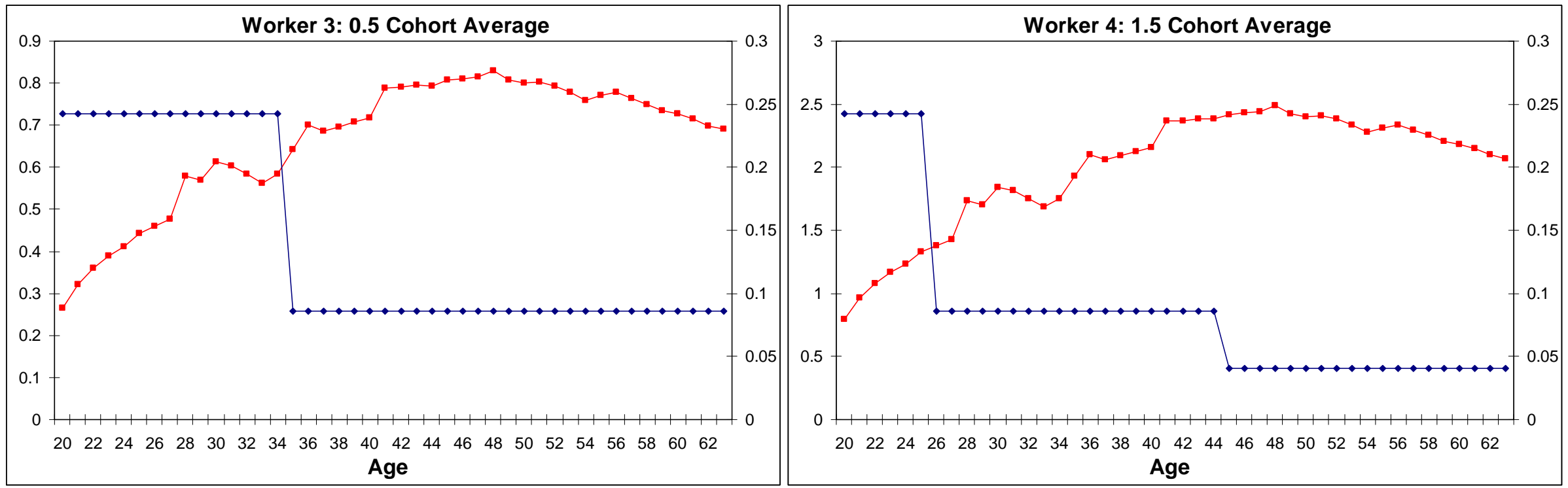
Figure 4

\section{Change in PAAW Balances}

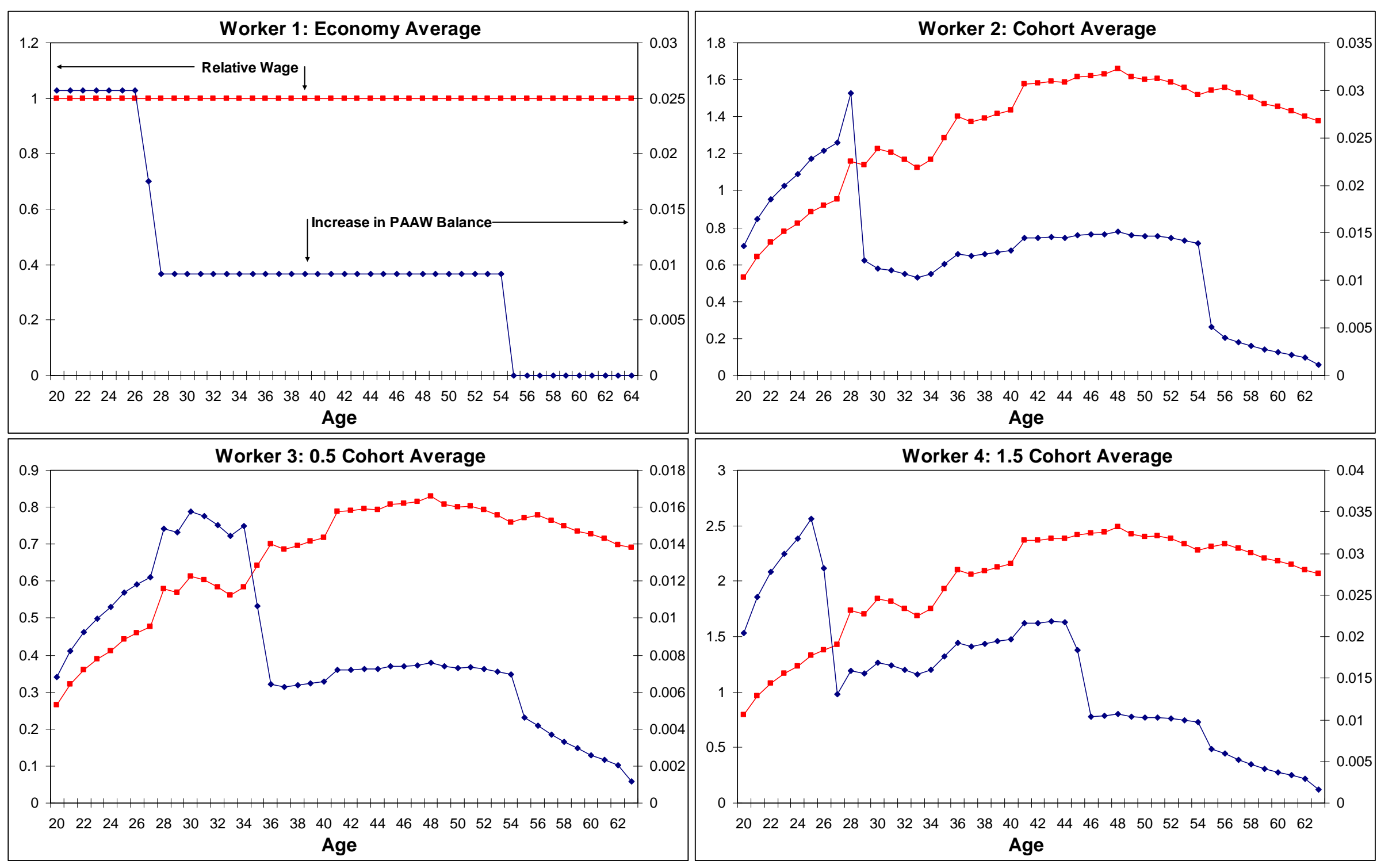




\section{PAAW Balances (PBAL)}
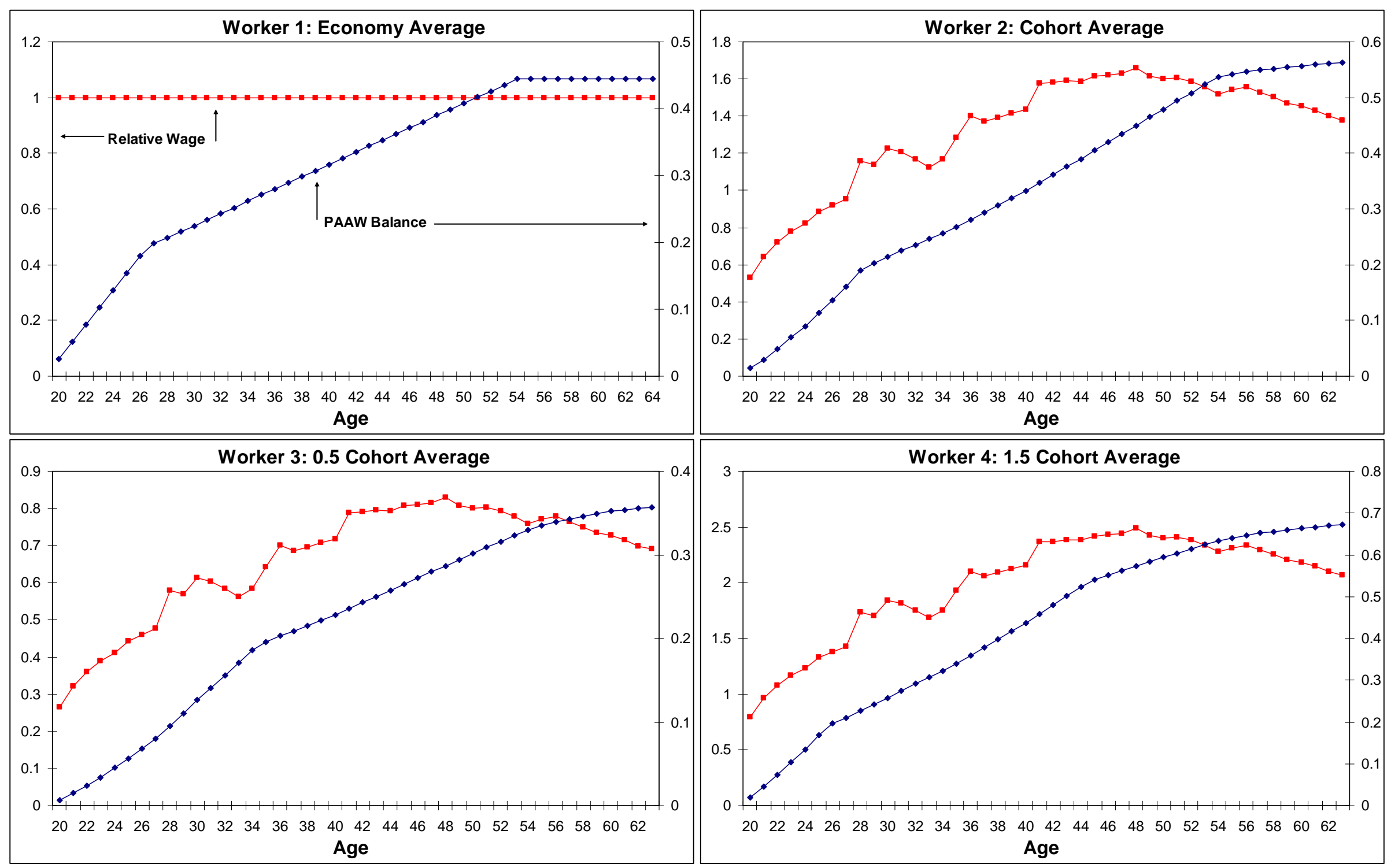
Figure 6

\section{PBAL Under Two Accrual Methods}

(for a worker with relative earnings of $\mathbf{1 . 7 5}$ for all ages)

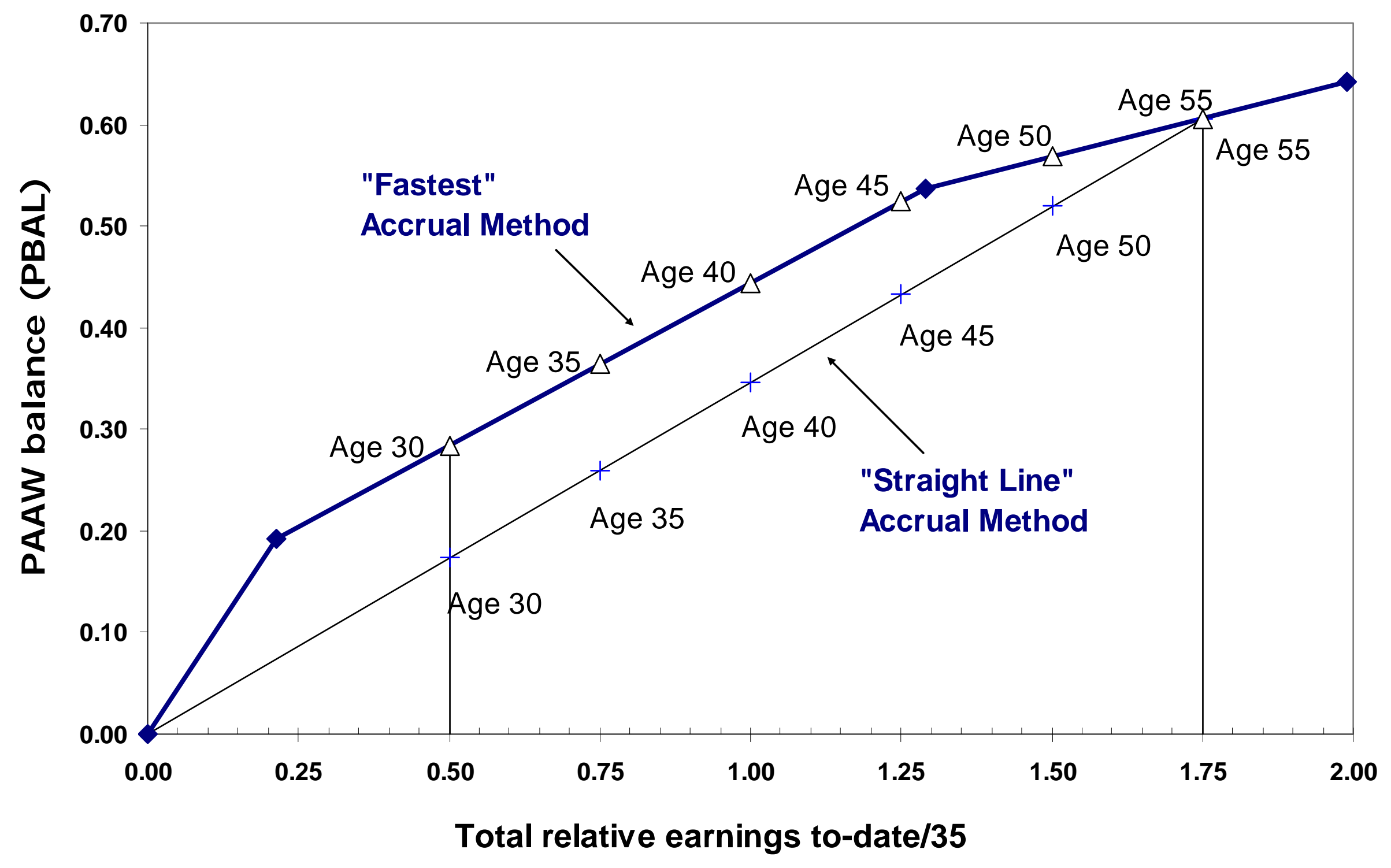


Figure 7

\section{PBAL Under Two Accrual Methods}
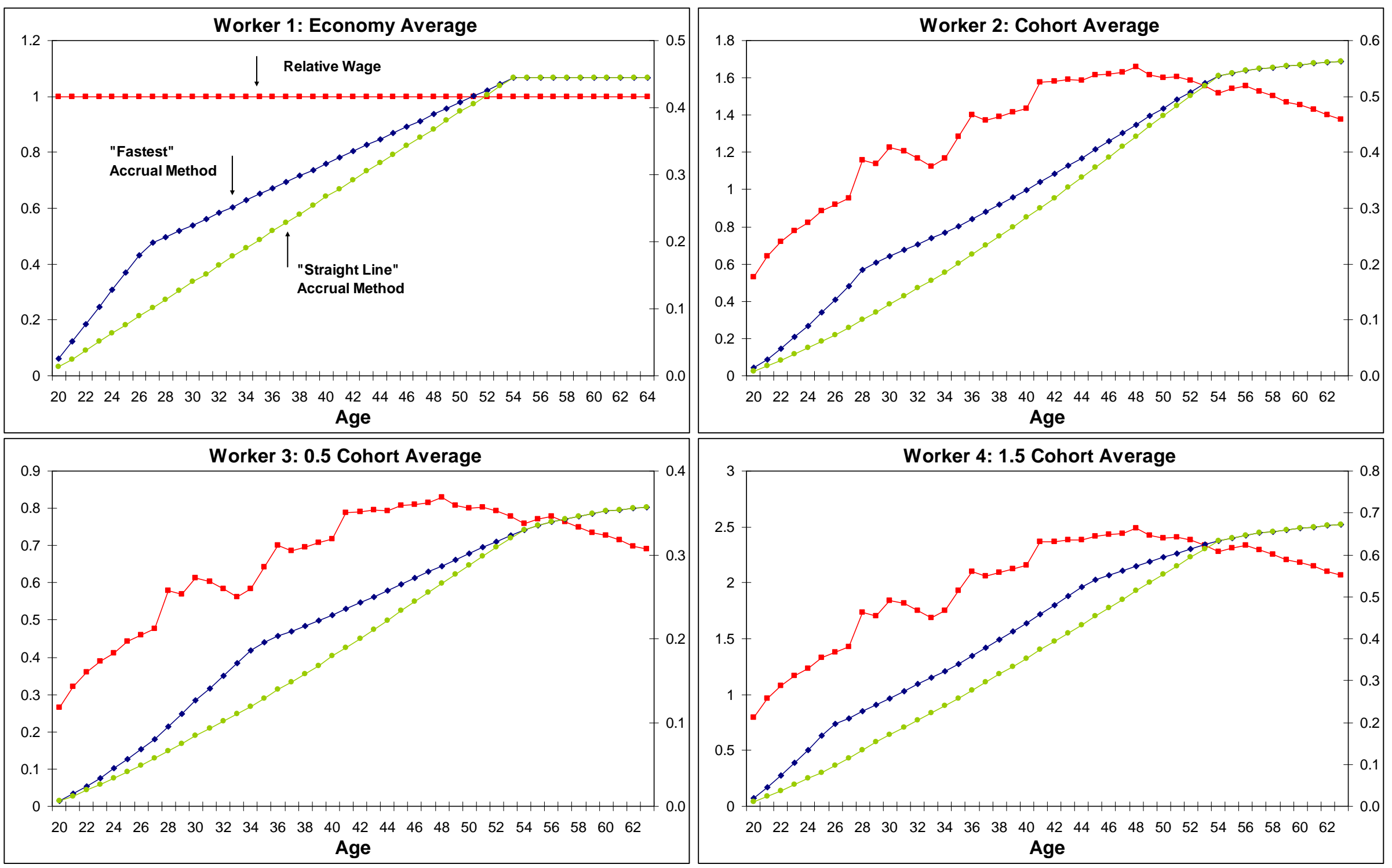
Figure 8

\section{Projected market price of one PAAW}

(under risk neutrality, measured in average wage units)

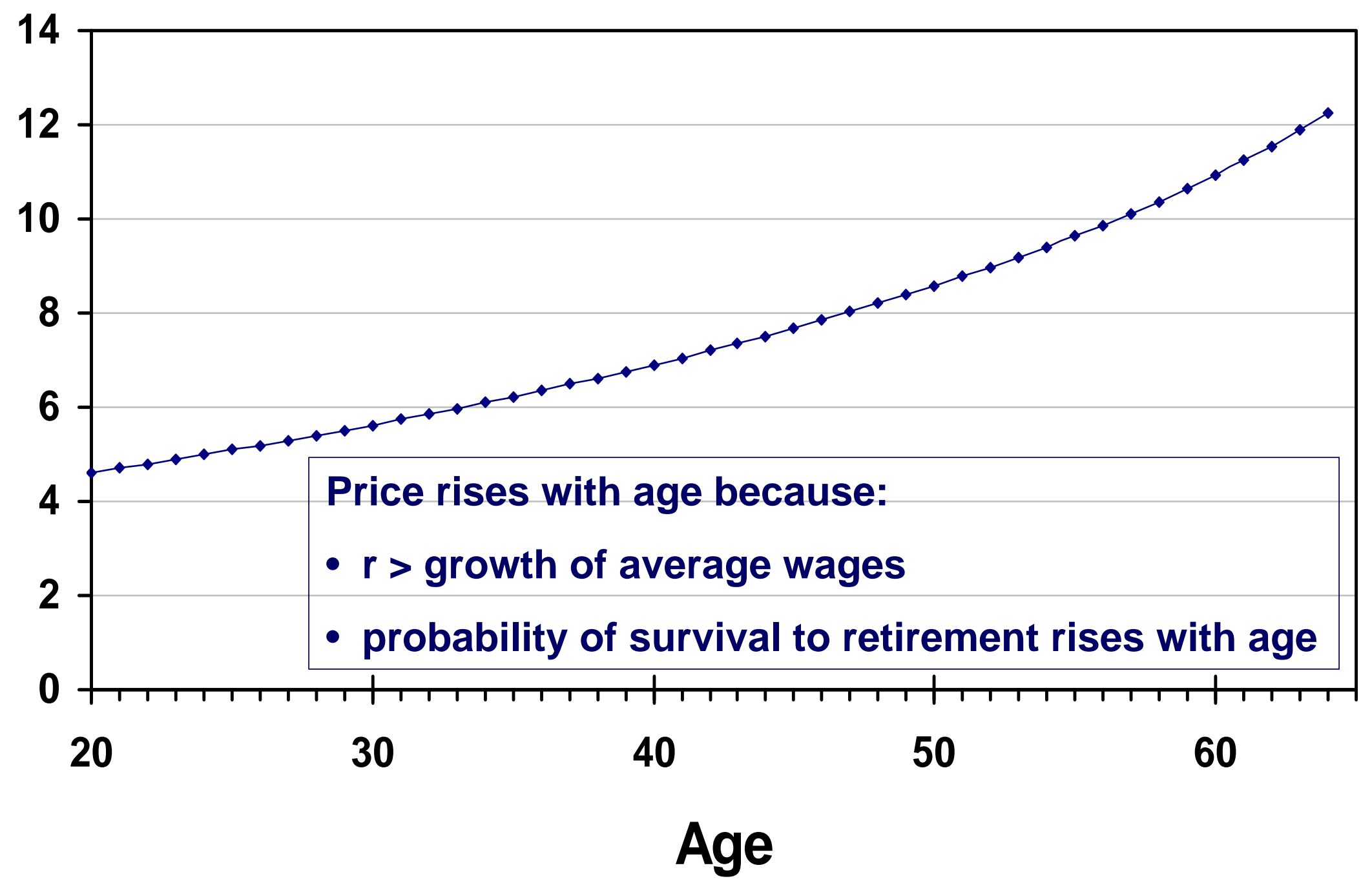


Figure 9

\section{Projected Market Value of Accrued PAAWs (measured in average wage units)}
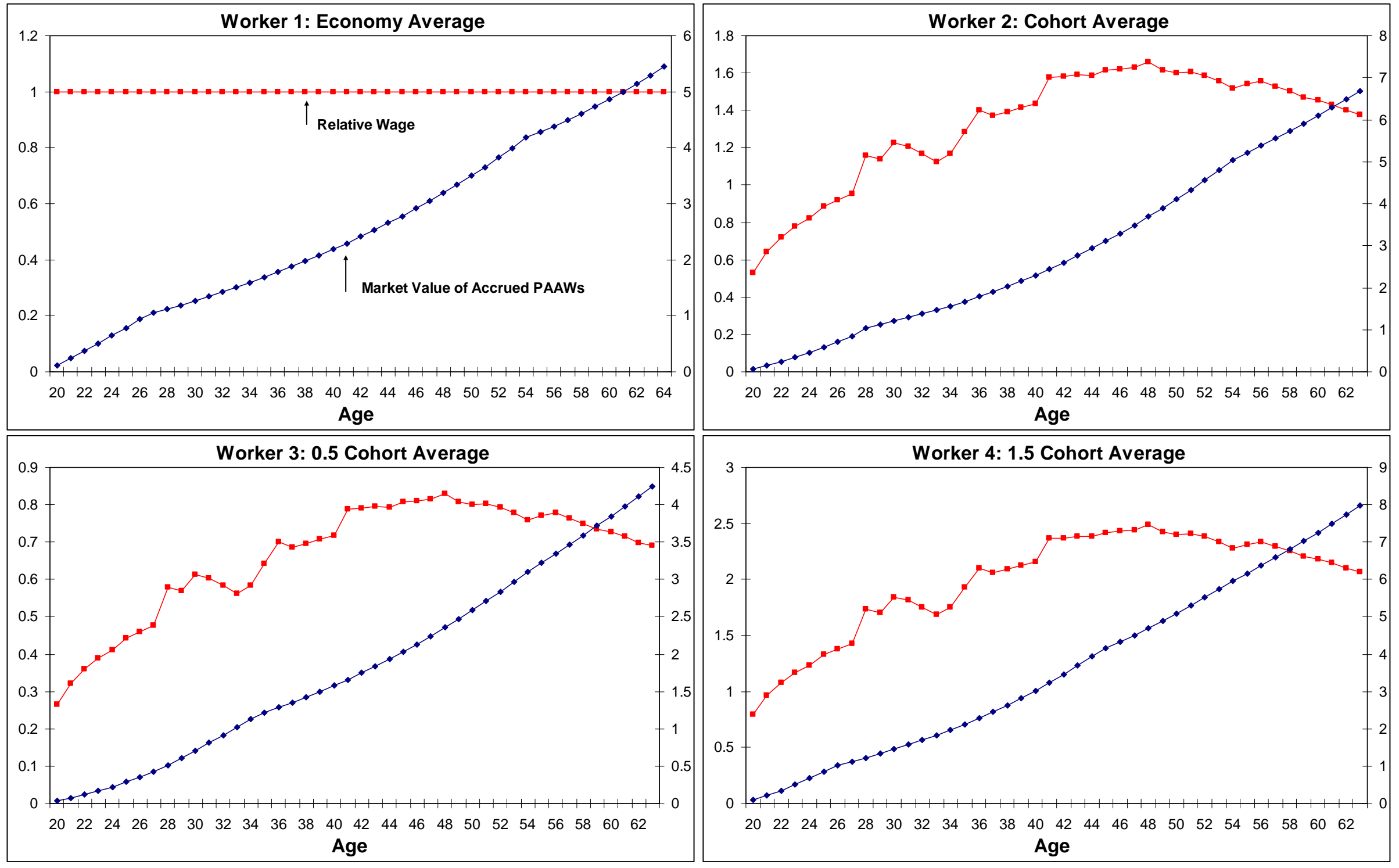


\section{Figure 10 Average Match Rate}

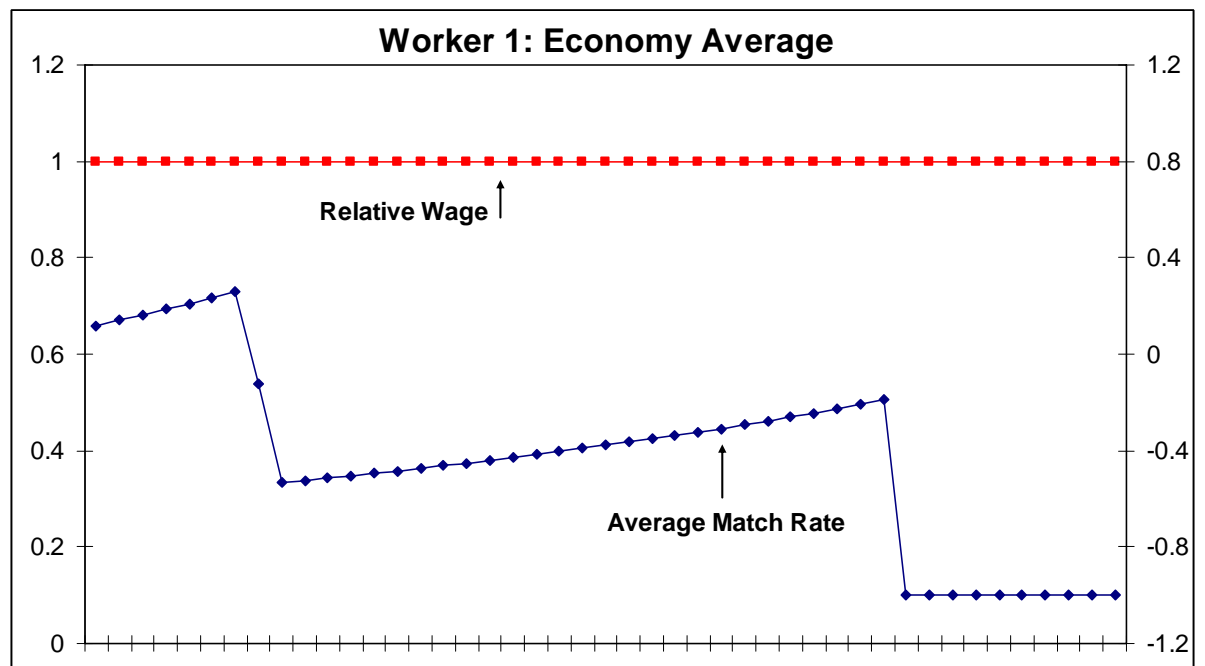

$\begin{array}{lllllllllllllllllllllll}20 & 22 & 24 & 26 & 28 & 30 & 32 & 34 & 36 & 38 & 40 & 42 & 44 & 46 & 48 & 50 & 52 & 54 & 56 & 58 & 60 & 62 & 64\end{array}$ Age

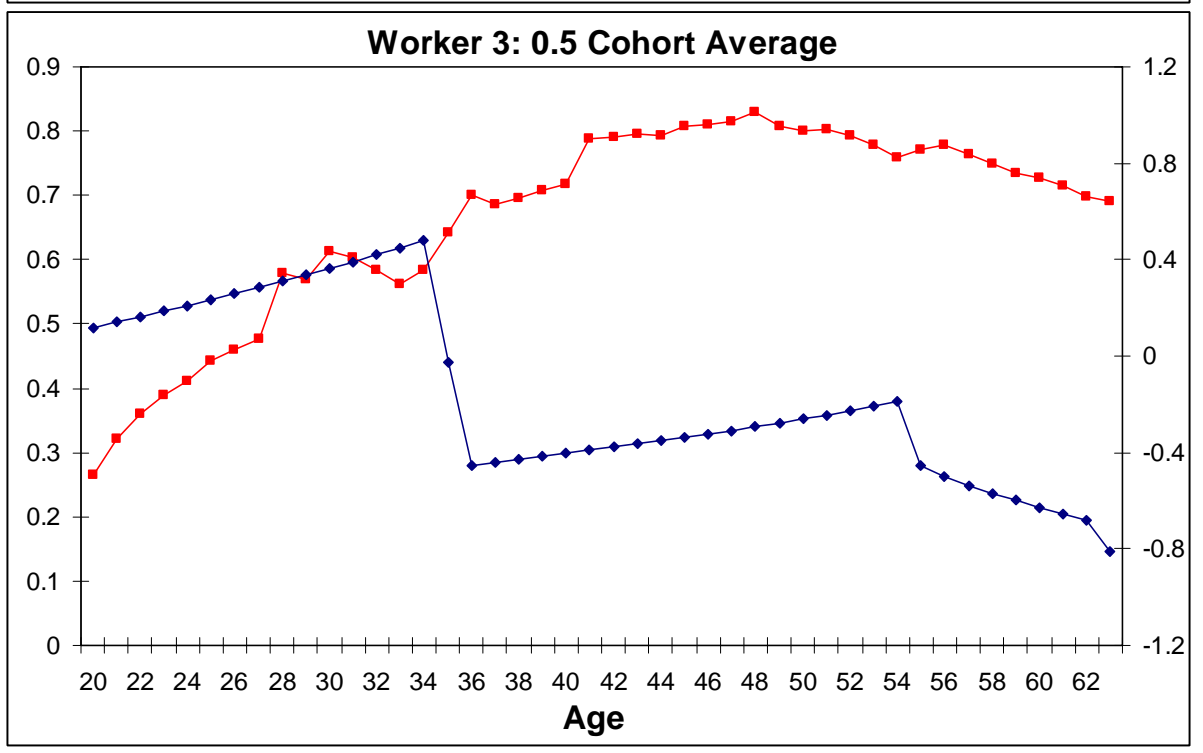

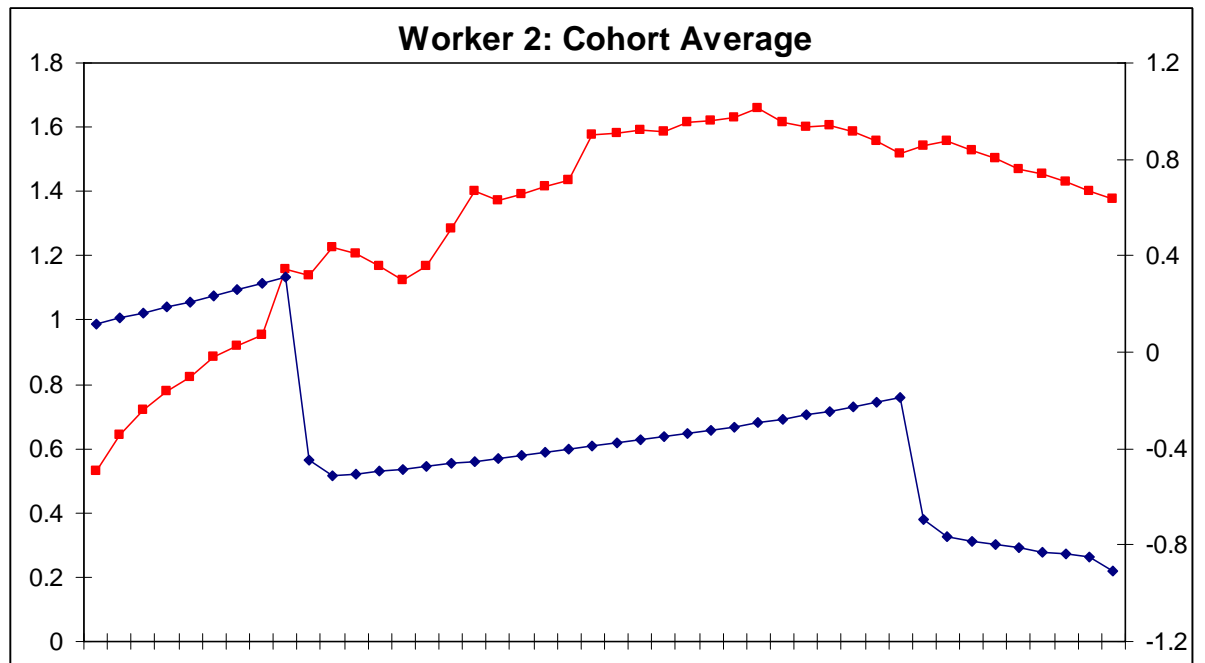

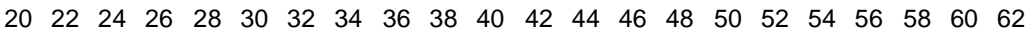

Age

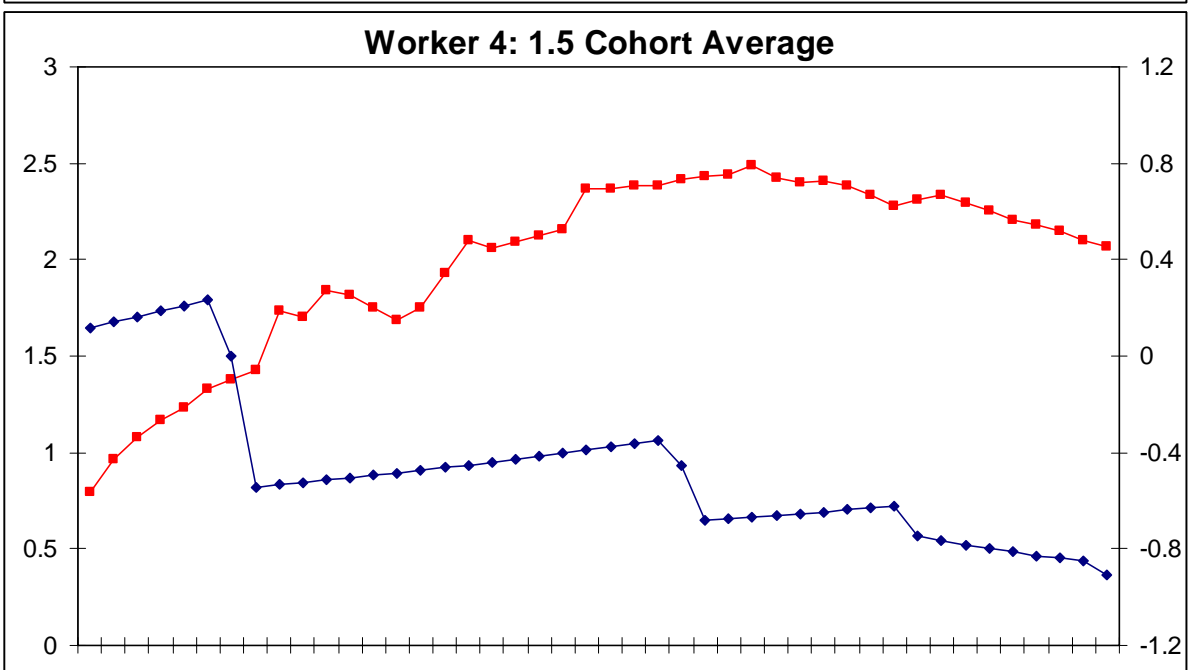

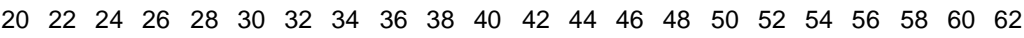

Age 
Figure 11

\section{Marginal Match Rate}

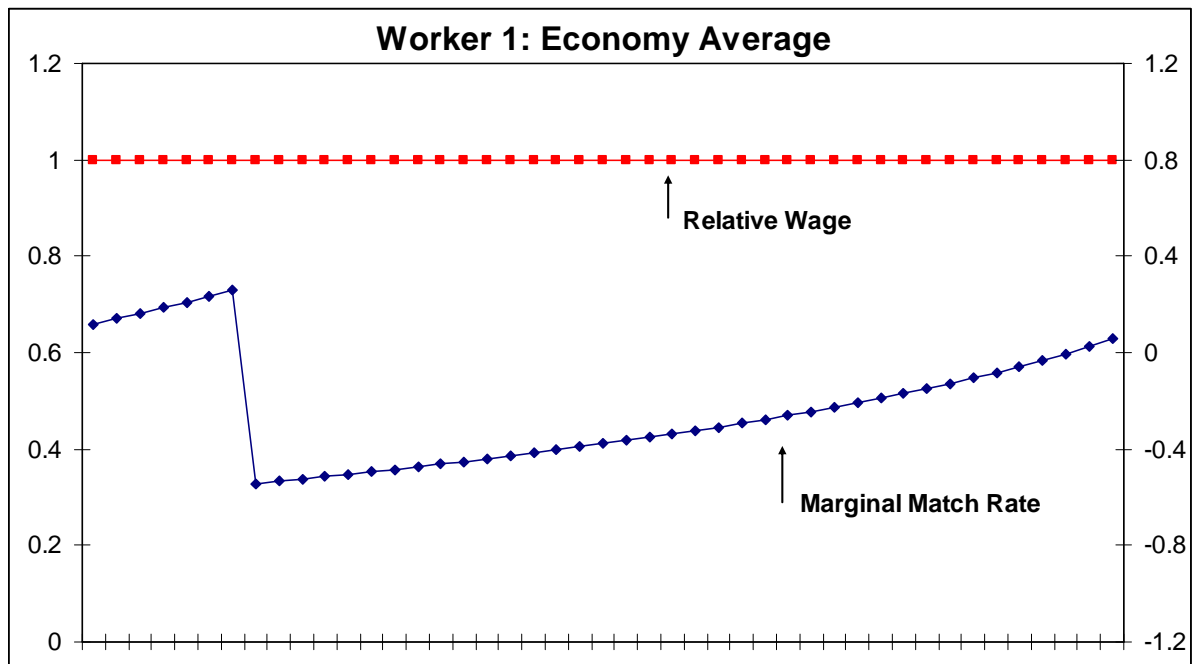

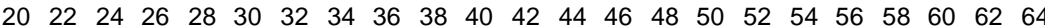
Age

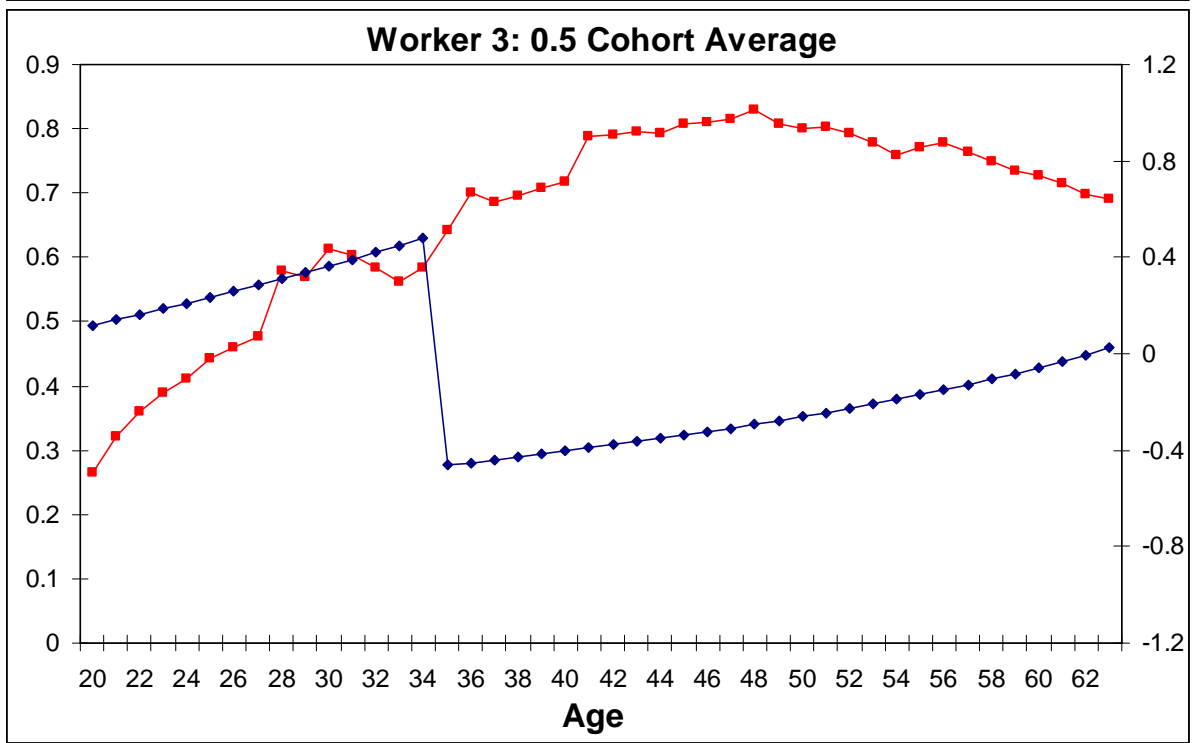

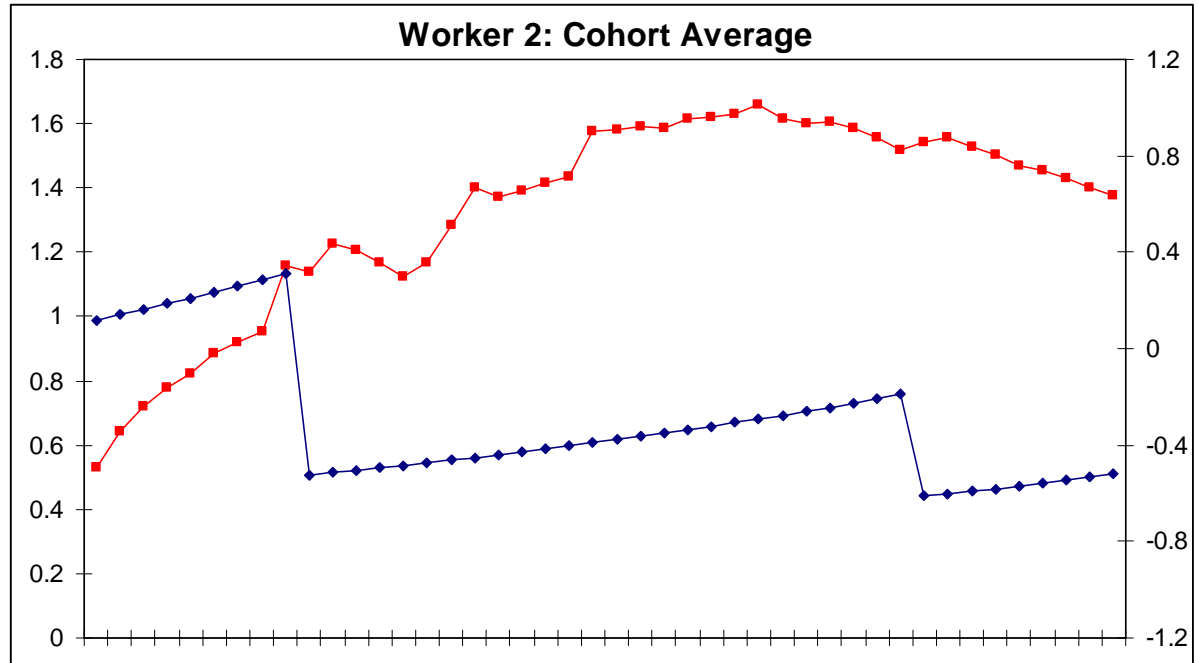

$\begin{array}{llllllllllllllllllllll}20 & 22 & 24 & 26 & 28 & 30 & 32 & 34 & 36 & 38 & 40 & 42 & 44 & 46 & 48 & 50 & 52 & 54 & 56 & 58 & 60 & 62\end{array}$ Age

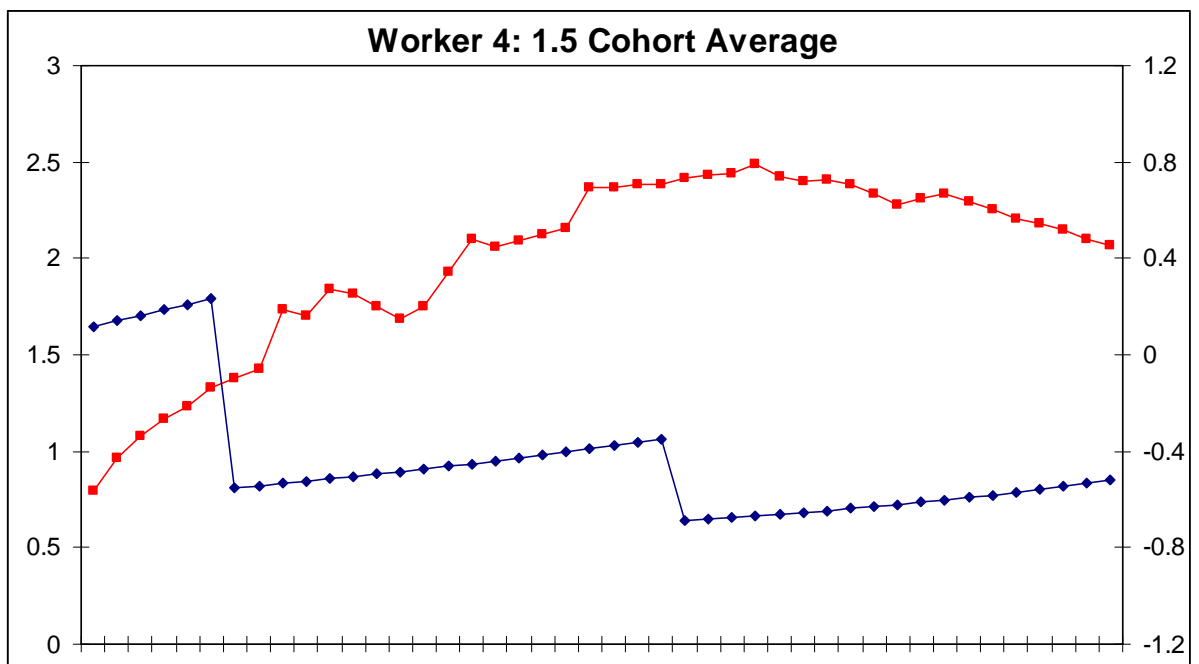

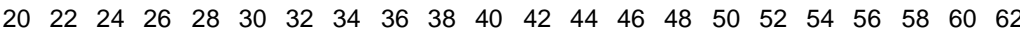
Age 


\section{Figure 12}

\section{Average Match Rate Under Two Accrual Methods}

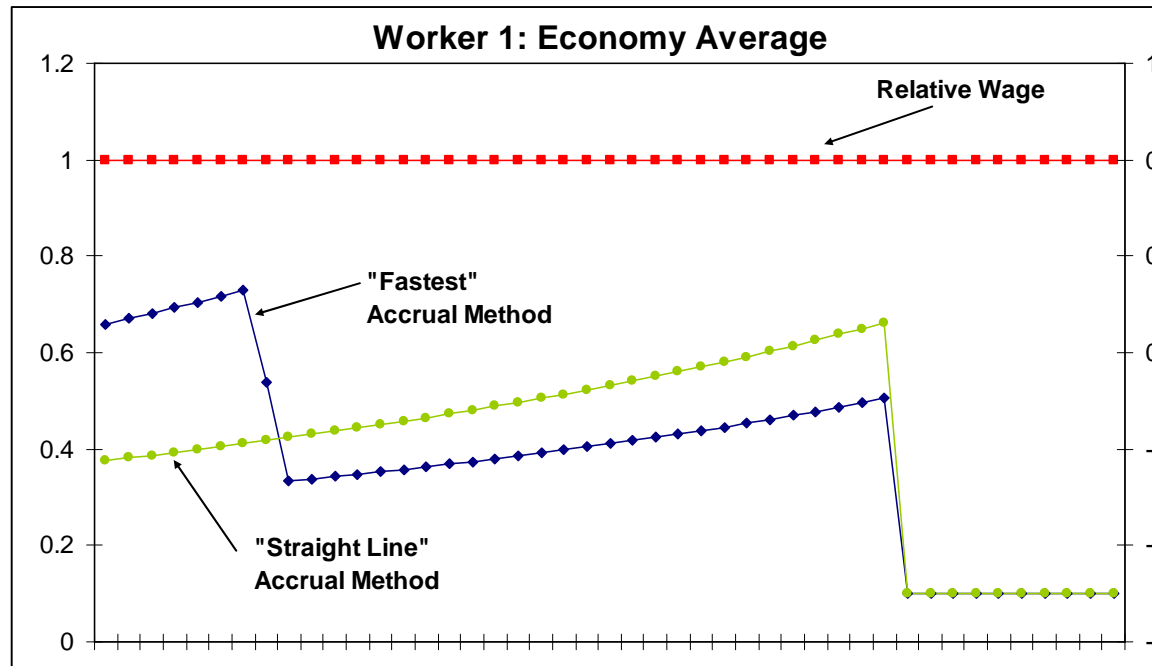

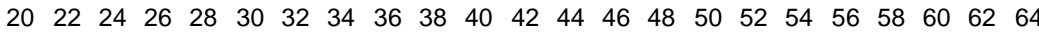
Age

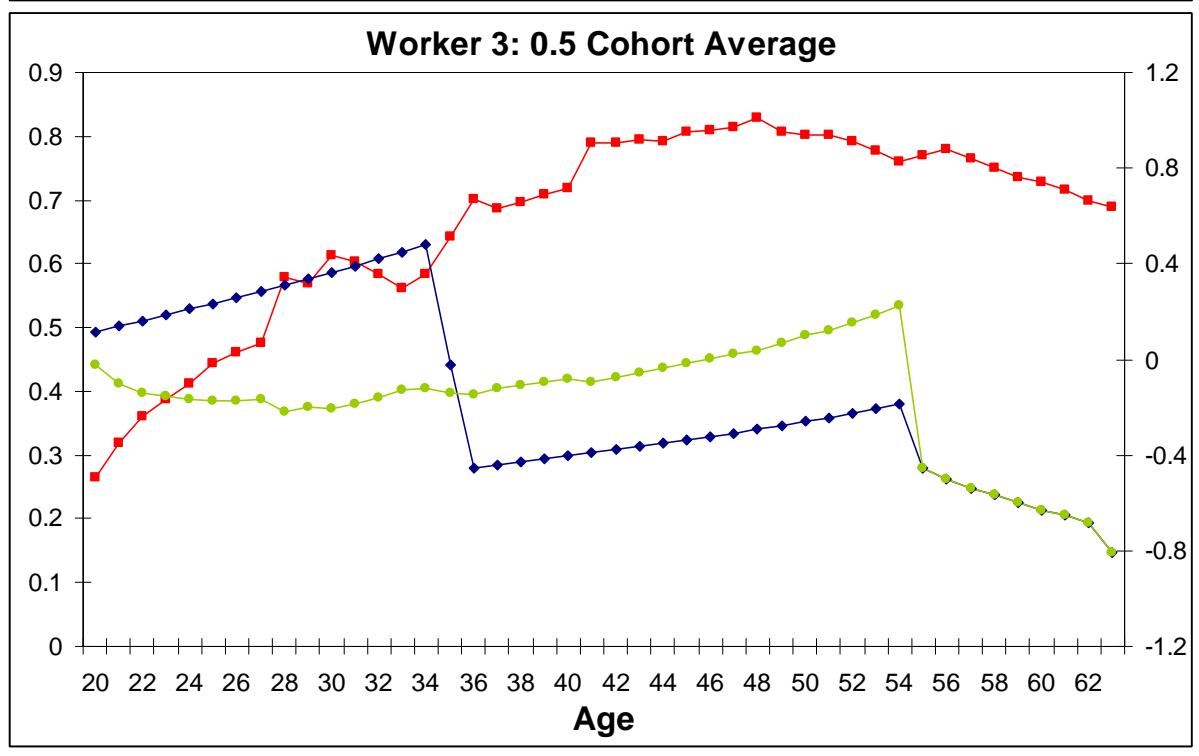

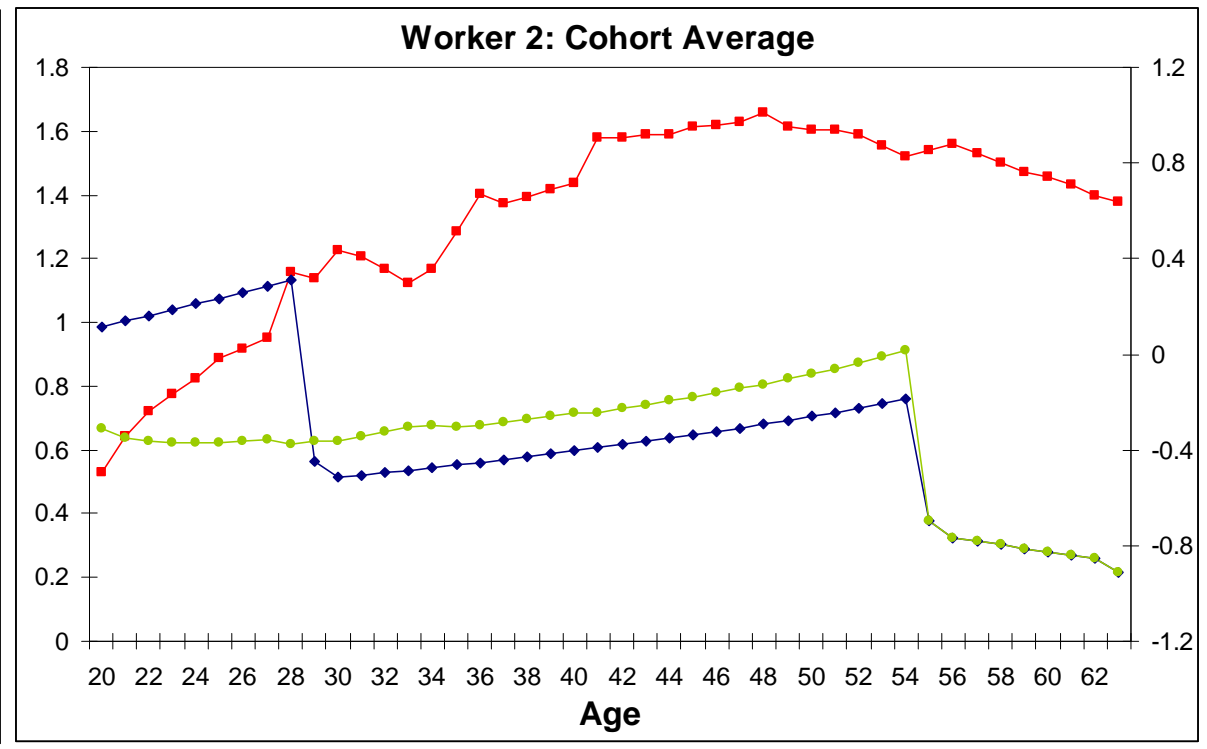

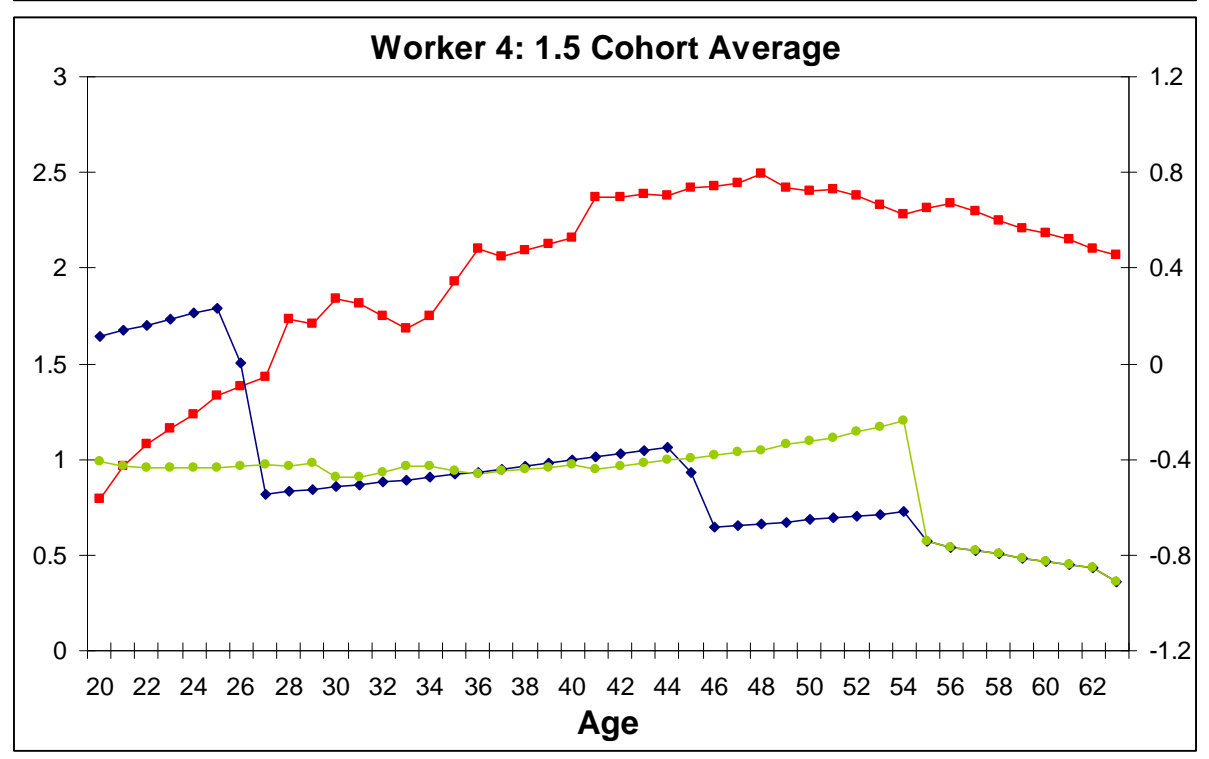




\section{Figure 13}

\section{Marginal Match Rate Under Two Accrual Methods}

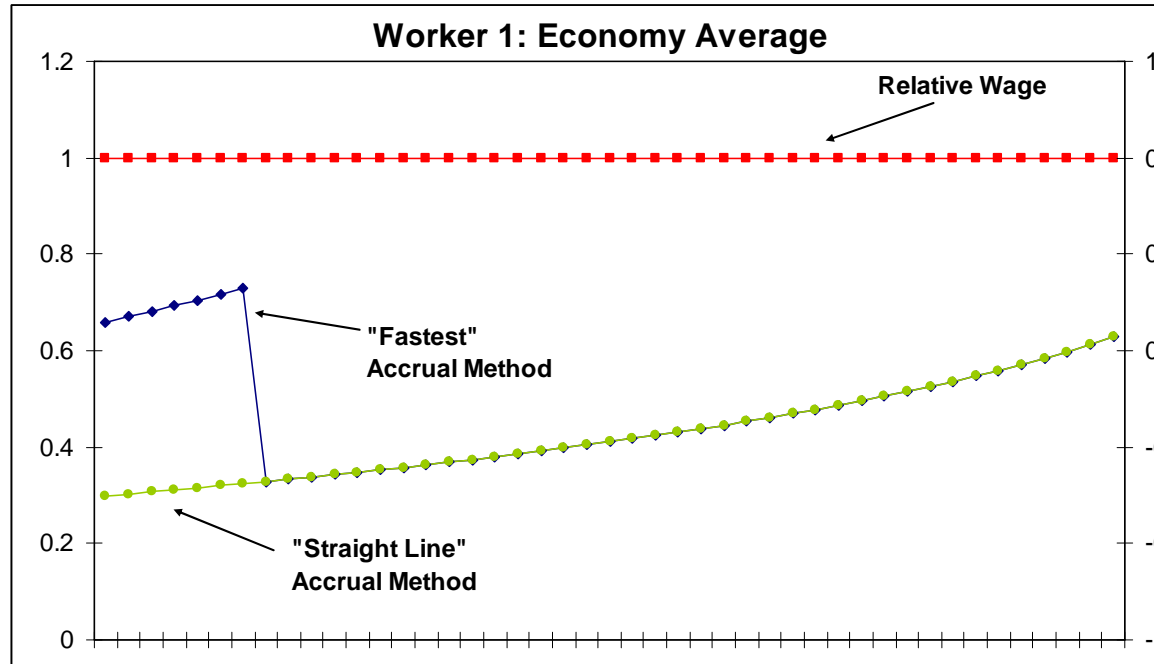

$\begin{array}{lllllllllllllllllllllll}20 & 22 & 24 & 26 & 28 & 30 & 32 & 34 & 36 & 38 & 40 & 42 & 44 & 46 & 48 & 50 & 52 & 54 & 56 & 58 & 60 & 62 & 64\end{array}$ Age

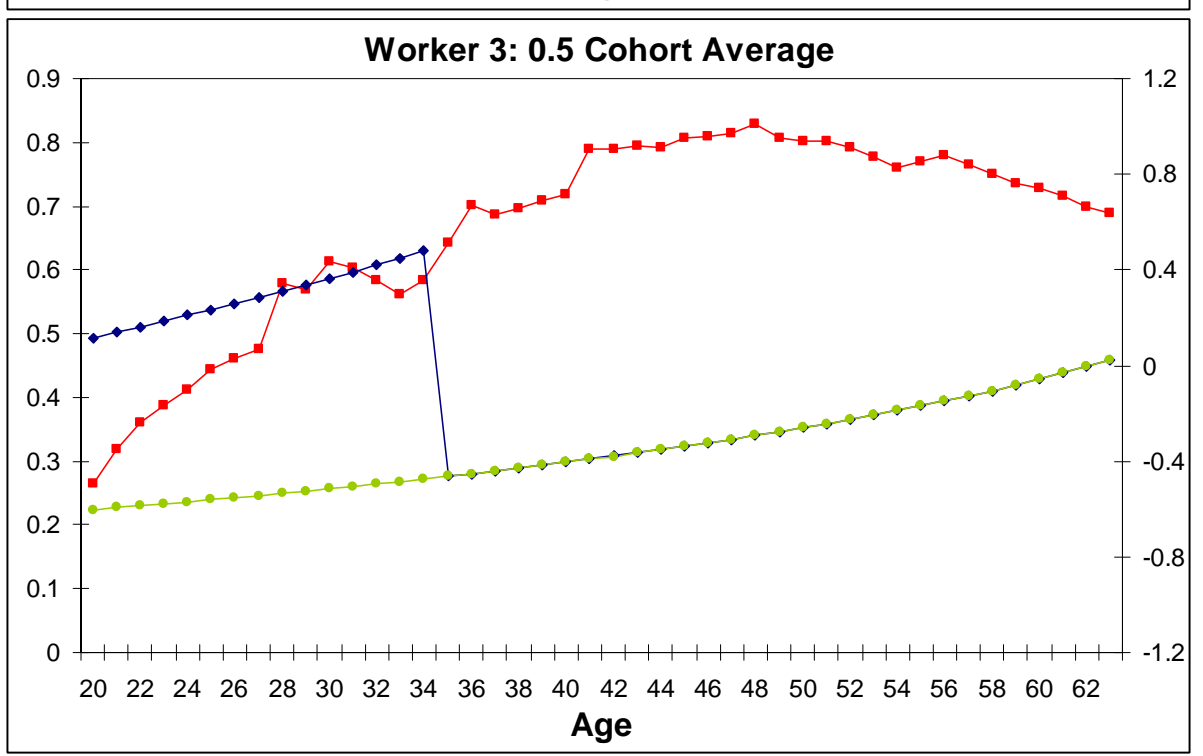

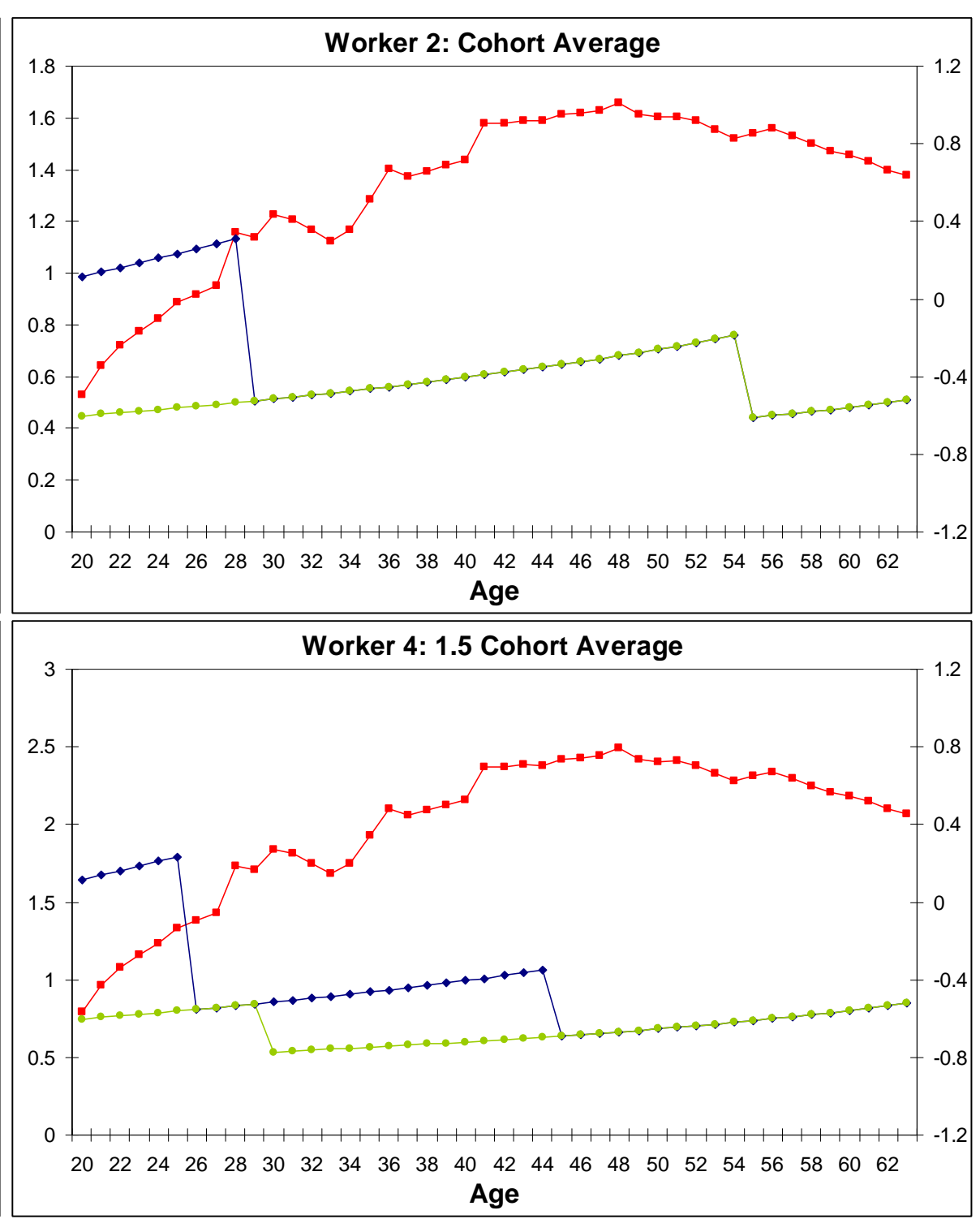




\section{Figure 14}

\section{Average Match Rates Under Automatic Balance}
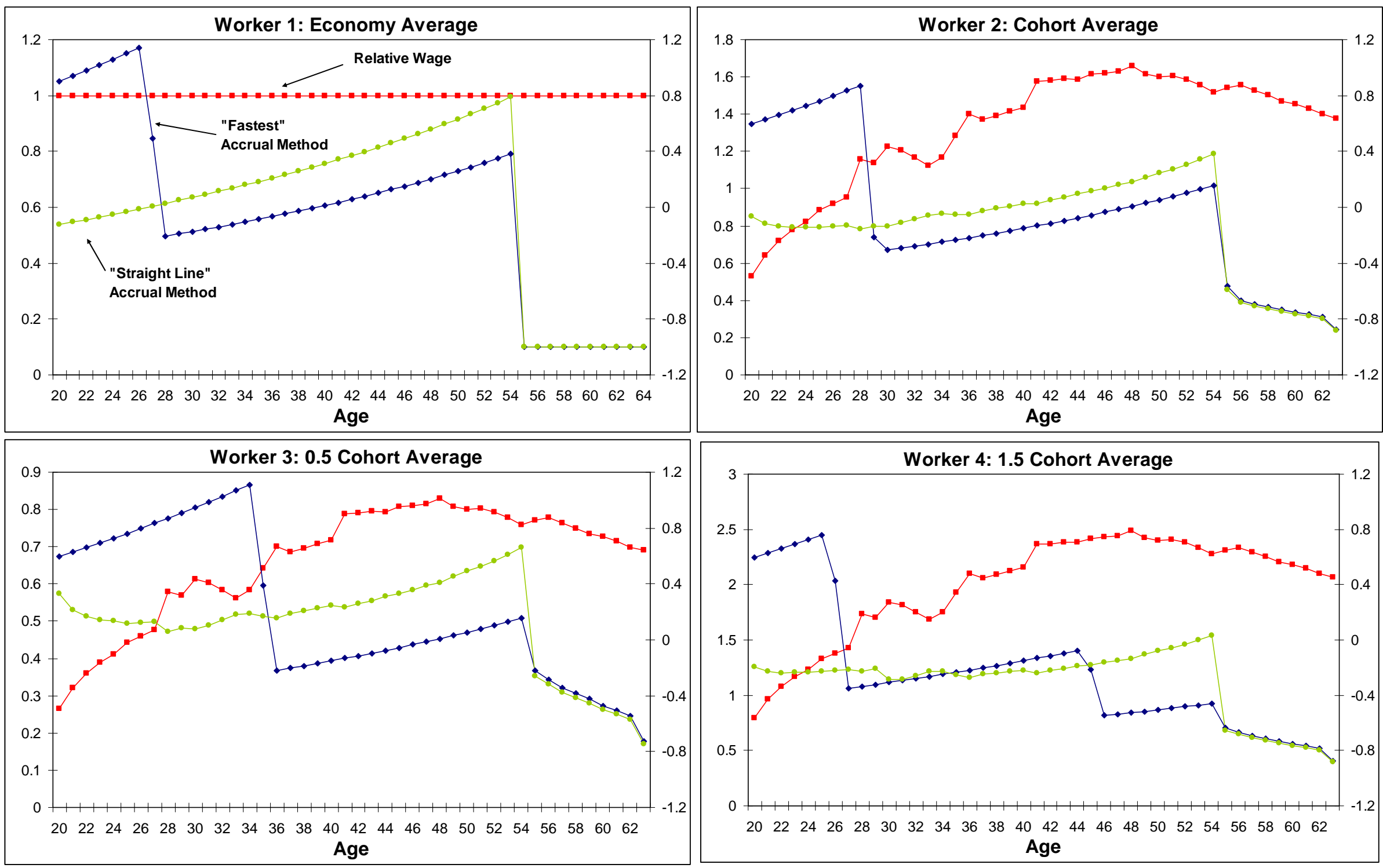


\section{Figure 15}

\section{Marginal Match Rates Under Automatic Balance}
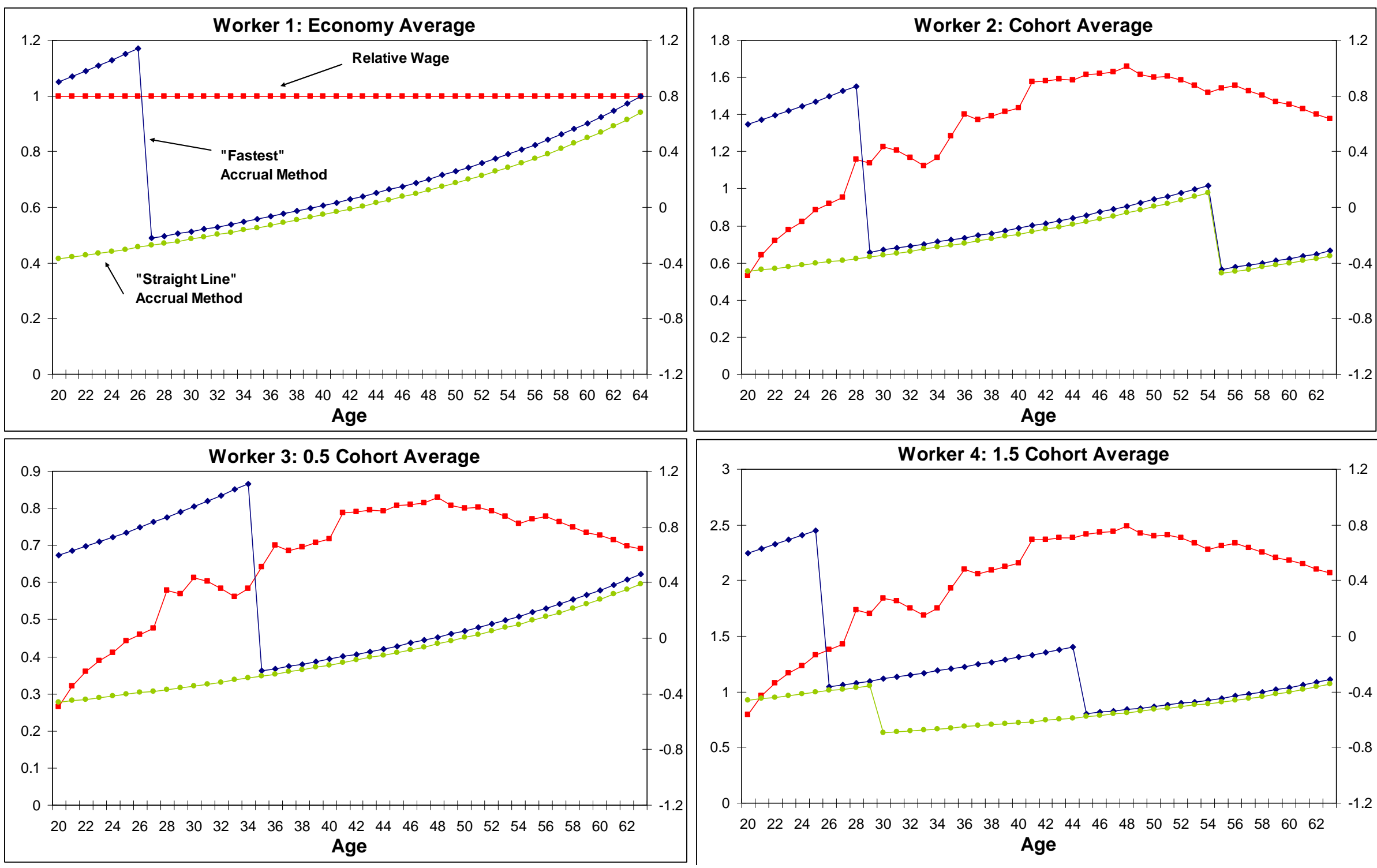